\title{
Exploiting vulnerabilities of cancer by targeting nuclear receptors of stromal cells in tumor microenvironment
}

\author{
Hong Sheng Cheng ${ }^{1 * \dagger}$, Jeannie Xue Ting Lee ${ }^{2 \dagger}$, Walter Wahli $i^{2,3,4}$ and Nguan Soon Tan ${ }^{1,2^{*}}$ (D)
}

\begin{abstract}
The tumor microenvironment is a complex and dynamic cellular community comprising the tumor epithelium and various tumor-supporting cells such as immune cells, fibroblasts, immunosuppressive cells, adipose cells, endothelial cells, and pericytes. The interplay between the tumor microenvironment and tumor cells represents a key contributor to immune evasiveness, physiological hardiness and the local and systemic invasiveness of malignant cells. Nuclear receptors are master regulators of physiological processes and are known to play pro-/anti-oncogenic activities in tumor cells. However, the actions of nuclear receptors in tumor-supporting cells have not been widely studied. Given the excellent druggability and extensive regulatory effects of nuclear receptors, understanding their biological functionality in the tumor microenvironment is of utmost importance. Therefore, the present review aims to summarize recent evidence about the roles of nuclear receptors in tumor-supporting cells and their implications for malignant processes such as tumor proliferation, evasion of immune surveillance, angiogenesis, chemotherapeutic resistance, and metastasis. Based on findings derived mostly from cell culture studies and a few in vivo animal cancer models, the functions of VDR, PPARs, AR, ER and GR in tumor-supporting cells are relatively well-characterized. Evidence for other receptors, such as RAR $\beta$, RORY, and FXR, is limited yet promising. Hence, the nuclear receptor signature in the tumor microenvironment may harbor prognostic value. The clinical prospects of a tumor microenvironment-oriented cancer therapy exploiting the nuclear receptors in different tumor-supporting cells are also encouraging. The major challenge, however, lies in the ability to develop a highly specific drug delivery system to facilitate precision medicine in cancer therapy.
\end{abstract}

Keywords: Nuclear receptors, Tumor microenvironment, Cancer-associated fibroblast, Myeloid-derived suppressor cells, Tumor-associated macrophage

\section{Background}

In human cells, there are 48 nuclear receptors (NRs) that play integral roles in numerous physiological functions such as metabolism, cell development, immunity, and stress response. Classically, following direct lipophilic ligand binding, NRs will recognize and bind to specific DNA motifs across the genome, which are known as NR response elements. The binding of an NR to its response element and transcriptional activation of target genes often require homodimerization of NRs or

\footnotetext{
* Correspondence: hscheng@ntu.edu.sg; nstan@ntu.edu.sg Hong Sheng Cheng and Jeannie Xue Ting Lee share $1^{\text {tt }}$ authorship ${ }^{1}$ School of Biological Sciences, Nanyang Technological University Singapore, 60 Nanyang Drive, Singapore 637551, Singapore

Full list of author information is available at the end of the article
}

heterodimerization with retinoid $\mathrm{X}$ receptor (RXR) coupled to the recruitment of coactivator proteins, although certain receptors are functionally active as a monomer [1, 2]. Independent of ligand binding, the activities of NRs can also be modulated by posttranslational modifications such as phosphorylation, ubiquitination, and SUMOylation, or indirect recruitment to the genome by other DNA-bound transcription factors via tethering mechanisms [2, 3]. Increasing evidence has also unveiled the pivotal roles of NRs in chromatin remodeling [4]. Furthermore, certain NRs such as progesterone receptor (PR) and peroxisome proliferator-activated receptor (PPAR) $-\gamma$ possess different isoforms resulting from alternative splicing. Variations in the tissue expression profile, ligand affinity and target genes

(c) The Author(s). 2019 Open Access This article is distributed under the terms of the Creative Commons Attribution 4.0 International License (http://creativecommons.org/licenses/by/4.0/), which permits unrestricted use, distribution, and 
between different isoforms have been reported, further enlarging the scope of the cellular events coordinated by NRs [5, 6] Hence, given the complex and multifaceted regulatory network coordinated by NRs, their impacts on human physiology are undoubtedly highly consequential.

In drug development, NRs are ideal therapeutic targets because their activities can be readily induced or repressed with small molecules that mimic their natural ligands, allowing fine manipulation of the biological functions or pathological processes controlled by the receptors. This possibility is particularly true for endocrine receptors such as thyroid hormone receptor (THR), vitamin D receptor (VDR), estrogen receptor (ER), androgen receptor (AR), glucocorticoid receptor (GR) and PR, as well as adopted orphan receptors such as farnesoid X receptor (FXR), RAR-related orphan receptor (ROR) and PPARs with well-characterized endogenous ligands. In this context, the involvement of NRs in various types of cancer has been extensively documented $[7,8]$. Clinically, strategies that aim to block $A R$ and ER, namely, androgen deprivation therapy and selective ER modulators, are widely employed to treat prostate and breast cancer, respectively, strongly supporting the practicality of NRs as druggable targets to improve cancer treatment outcomes.

Recently, the tumor microenvironment (TME) has swiftly garnered the attention of the cancer research community and has been accepted as the key contributor to tumor progression. The interplay between TME and the tumor epithelium empowers the aggressiveness of tumor cells by enhancing tumor proliferation, chemoresistance, immune evasion and metastatic tendency [9]. Other than cancer cells, TME is populated by highly heterogeneous groups of cells, including cancerassociated fibroblasts (CAFs), tumor-associated macrophages (TAMs), endothelial cells, adipose cells, myeloid-derived suppressor cells (MDSCs), and other immune and inflammatory cells. All members of the microenvironment function cooperatively with the assistance of a vast variety of cytokines, chemokines, growth factors, and other signaling molecules, to compose a dynamic and ever-evolving network that offers sharpened stress responses and enhanced survivability to the malignant cells [9].

In this context, although NRs in tumor cells have been widely studied, their implications in TME are comparatively underappreciated. Given the pro-oncogenic roles of TME as well as the pronounced regulatory effects and excellent druggability of NRs, understanding the roles of these receptors in TME is of great interest. The implicated NRs in various tumor-supporting cells in TME presented in this review are illustrated in Fig. 1. Knowledge of the NR expression profile not only helps to provide a fundamental understanding in the realm of cancer biology but also harbors enormous clinical value in cancer therapy. Thus, this review aims to highlight key findings of the biological functions of NRs in different cell types presented in TME in relation to their pro-/ anti-tumor activities. The empirical findings are also discussed concerning the challenges, limitations and future direction of the current research paradigm with high hopes of developing a new anti-cancer strategy by exploiting NRs in TME.

\section{Cancer-associated fibroblasts/myofibroblasts as key accomplices in tumor malignancy Regulatory roles of CAF steroid hormone nuclear receptors in hormone-dependent cancers}

Forming one of the most abundant cell populations in TME, CAFs are known to be pivotal modulators of tumorigenicity and cancer progression. A much larger number of studies have been conducted on CAFs than on other stromal cells in TME, particularly in terms of steroid hormone NRs. Therefore, this review of the actions of NRs in CAFs is subdivided into two parts in accordance with steroid and nonsteroid hormone NRs.

CAFs are primarily composed of fibroblasts and myofibroblasts, of which the latter displays a mixed phenotype of fibroblast and smooth muscle cells by having a prominent rough endoplasmic reticulum of fibroblasts and contractile filaments (e.g., smooth-muscle actin) of smooth muscle cells [10]. The crosstalk between the tumor and CAFs assists tumor cells in acquiring unique characteristics such as enhanced proliferation, metastatic and angiogenic properties, immune evasion and chemoresistance $[11,12]$. It has been postulated that dysregulated activities of certain nuclear factors in CAFs could contribute to their tumor-supportive roles. CAFs have markedly distinct gene expression profiles of NRs compared with their normal cognate fibroblasts. Indeed, CAFs isolated from human breast tumors exhibit vastly different NR fingerprints compared with normal breast fibroblasts, as exemplified by the downregulation of THR- $\beta$, VDR, ROR- $\alpha$, and PPAR- $\gamma$ in CAFs [13]. Furthermore, NR signatures also differ among CAFs isolated from different types of tumors [13-15]. Such disparities in NR profiles could be an intrinsic characteristic of fibroblasts at different anatomical positions, or due to cellular signals released by different host cancer cells and other surrounding stromal cells. In this context, our recent study using clinical cutaneous squamous cell carcinoma has confirmed the differential gene expression of NRs in CAFs compared with normal fibroblasts [15]. We have also shown that the transcriptomes of tumor cells cocultured with CAFs can be altered by reversing the expression pattern of selected NRs, namely, PPAR $\beta / \delta$, VDR, AR and retinoic acid receptor (RAR)- $\beta$ receptor, to result in functional changes such as impaired invasiveness, 


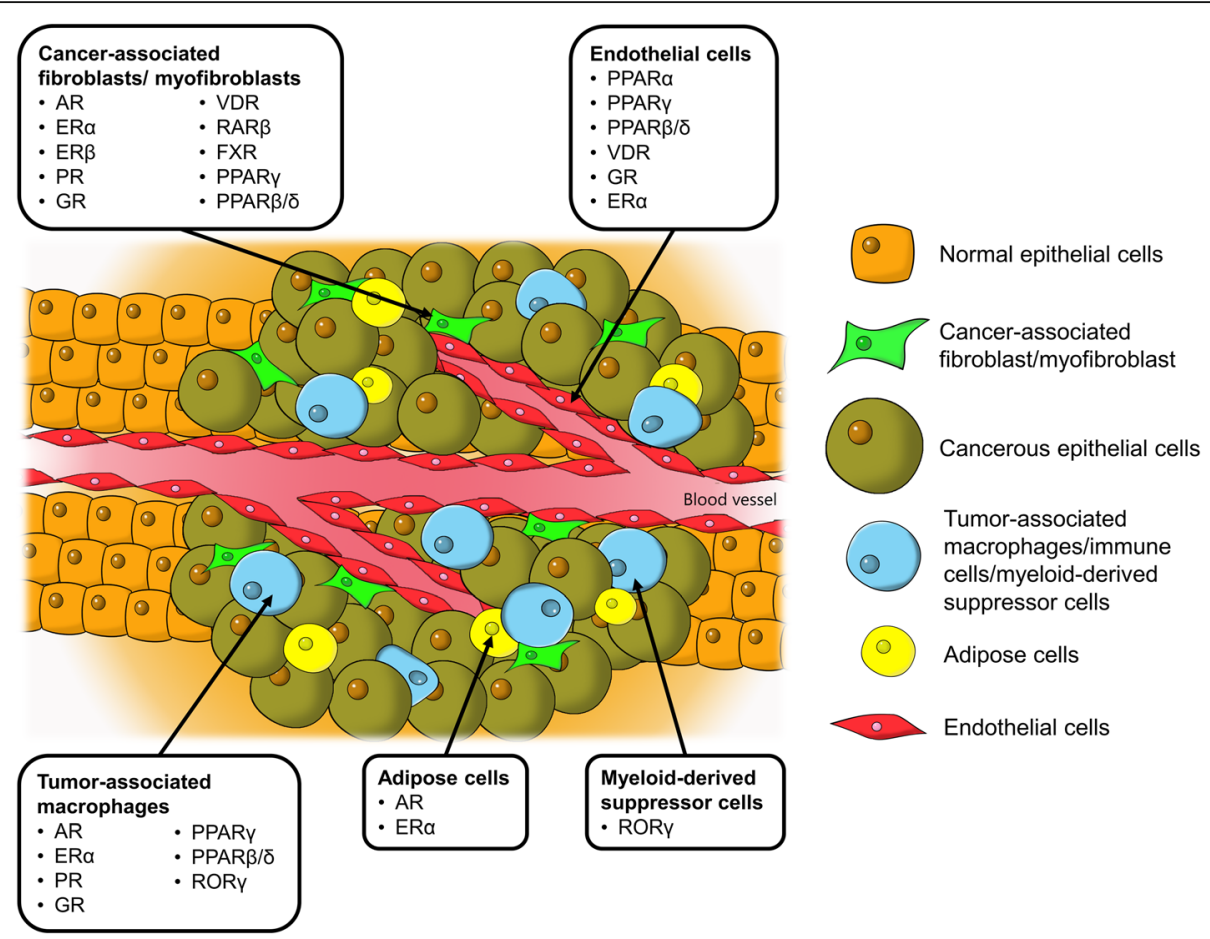

Fig. 1 Tumor microenvironment, tumor-supporting cells and the identified nuclear receptors in cancer progression. AR, androgen receptor; ER, estrogen receptor; FXR, farnesoid X receptor; GR, glucocorticoid receptor; PPAR, peroxisome proliferator-activated receptor; PR, progesterone receptor; ROR, RAR-related orphan receptor; VDR, vitamin D receptor

reduced proliferation, and altered energy metabolism and redox response [15]. More importantly, when the squamous cell carcinoma cultures are exposed to conditioned medium from CAFs pretreated with either RAR $\beta$ or AR antagonists, the CAF-induced cisplatin resistance is completely abolished [15]. Our study strongly supports the druggability of NRs in TME, notably AR and RAR $\beta$, which can mediate a CAF-directed cancer therapy.

In line with our findings, AR in the tumor stroma has been consistently found to be a predominant factor in the prognosis of prostate cancer [16]. Nevertheless, unlike squamous cell carcinoma, in which the inhibition of AR of CAFs could be beneficial, low levels or loss of AR in the stromal cells of prostate cancer are associated with poorer clinical outcomes [17-22]. Such an association is mind-boggling given that androgen deprivation therapy, which aims to suppress AR signaling in tumor cells, often serves as the frontline treatment of prostate cancer [23]. Genome-wide CHIPseq has revealed that AR in prostate CAFs has distinct binding sites and binding sequence motifs compared with tumor cells, suggesting differences in AR-regulated genes between the two cell populations [24]. This finding could explain the discrepancy in AR function between prostate CAFs and cancer cells. The tumor stroma liberates various androgen-responsive growth factors and cytokines that modulate the cell fate, proliferation and drug sensitivity of prostate cancer cells [25-27]. These paracrine factors are favorable for the growth of tumor cells present in this environment. Although ablation of ARs in CAFs could attenuate cancer proliferation [28], the loss of AR signaling activity is also linked to the onset of metastatic phenotypes such as increased stemness, enhanced cell migration and weakening of the extracellular matrix (ECM) structure and integrity $[22,29,30]$. As a result, the suppression of AR in CAFs may potentially exacerbate the epithelial-mesenchymal transition and metastasis of prostate cancer, underpinning the association of AR loss in CAFs with adverse clinical outcomes in prostate cancer progression. In short, the pathological roles of AR in CAFs are well-implicated in the development of prostate cancer, making it an attractive therapeutic target. However, considering the opposite effects of AR blockade in tumor and stromal cells, an ideal anti-androgenic agent should decrease tumor AR but enhance stromal AR activity [16]. It is also worth mentioning that the current understanding of AR in CAFs is mostly derived from hormone-dependent tumors, especially prostate and breast cancers $[16,31]$. Thus, in light of the evidence mentioned above, it is worthwhile to extend research on $\mathrm{AR}$ to other types of tumors to better characterize its roles in cancer biology.

In addition to AR, steroid hormone NRs in CAFs, including $E R \alpha$ and $\beta, P R$ and GR, are also relatively well-studied. The expression of ER $\alpha$ has been detected 
in the CAFs of breast [13], endometrial [32], cervical [33] and prostate cancers [34], but not in colorectal carcinoma [35]. However, the clinical implications of $\mathrm{ER} \alpha$ are diverse. In some studies, ER $\alpha$-expressing CAFs have been reported to promote prostate and endometrial cancer cell proliferation [32, 36]; in other studies, CAFs attenuated prostate tumor cell invasiveness and immune cell infiltration by altering the levels of anti-angiogenic factors, ECM remodeling factors as well as chemokines, in addition to conserving chemosensitivity in certain breast cancer cell lines [37-39]. Similarly, divergent results have also been obtained in clinical biopsies, in which one association study found a positive correlation between ER $\alpha$ expression in CAFs with advanced prostate cancer stage [34], while the reverse trend was found in cervical cancer [33]. Despite these perplexing findings, a recent comparative transcriptomic study demonstrated differential expression patterns between CAFs isolated from early- and late-stage cervical cancer, with the latter being more metabolically and proliferatively active upon estradiol exposure [40]. Treatment with ER antagonists, namely, ICI182780 and methylpiperidino pyrazole, not only reverses the aforementioned changes but also suppresses the expression of genes linked to angiogenesis and cell adhesion [40]. Additionally, liver receptor homolog-1 (LRH-1), which is an orphan NR, is transcriptionally responsive to estrogen treatment and ER $\alpha$ activation [41]. In breast cancer-derived CAFs, LRH-1, which is highly expressed in these cells, can upregulate aromatase (CYP19) gene expression [13, 42]. This observation is indicative of an ER $\alpha$-mediated loop of estrogen biosynthesis via LRH-1 in CAFs, which may contribute to the increased tumor cell proliferation. Hence, disrupting the paracrine signaling directed by ER $\alpha$ in CAFs may be beneficial, making NR an exploitable target for cancer therapy. However, further investigation is warranted to clarify the conflicting results about the tumorigenic properties of ER $\alpha$.

While ER $\alpha$ is well-implicated in TME of many hormone-dependent cancers, its role is less pronounced in the CAFs of breast cancer, likely because its expression is predominantly localized in the tumor epithelium instead of the surrounding fibroblasts [43-45]. In contrast, $E R \beta$, which is the other ER isotype, is widely found in the breast cancer stroma $[35,46]$. Despite their structural similarities, the bioactivities of $E R \alpha$ and $\beta$ in tumor epithelium are largely counteractive, whereby ER $\beta$ is anti-proliferative and ER $\alpha$-antagonizing $[47,48]$. Whether $E R \beta$ in CAFs also confers an anti-tumor effect is uncertain. One study revealed that progesterone and epidermal growth factor receptors are highly expressed in the uterine stroma of ER $\beta$-knockout mice, especially when $17 \beta$-estradiol and progesterone are coadministered [49]. This phenomenon contributed to the hyperproliferation and impaired cellular differentiation observed in the uterine epithelium of ER $\beta$-knockout mice [49]. Conversely, PR also exhibits ER $\alpha$-antagonizing properties in tumor cells [50]. Its expression in cancer-associated stroma is repressed in comparison to benign stroma in prostate glands [51, 52]. Stromal PR actively takes part in stromal cell differentiation [52]. Although conditioned medium from PR-positive CAFs has a negligible effect on prostate cancer cell proliferation, cell motility and migration are vastly inhibited via the suppression of stromal-derived factor-1 and interleukin (IL)-6 [51]. These findings highlight the importance of stromal ER $\beta$ and PR in stroma-tumor epithelium crosstalk in modulating cancer progression, but tissue-specific inhibition or activation of these NRs in CAFs is imperative to outline the feasibility of exploiting them as therapeutic cancer targets.

Next, GR is differentially expressed in TME compared with normal tissues [53], with remarkably high expression in CAFs [54, 55]. In cancer-associated myofibroblasts, treatment with dexamethasone successfully induces nuclear translocation of GR, resulting in an anti-inflammatory phenotype marked by the repression of IL- $1 \beta$, monocyte chemoattractant protein $1, \mathrm{C}-\mathrm{C}$ motif ligand 5 , tumor necrosis factor- $\alpha$ (TNF $\alpha)$ and intercellular adhesion molecules [56]. Coincidentally, several pro-invasive paracrine signals, such as tenascin $C$, hepatocyte growth factor, transforming growth factor $\beta$ (TGF $\beta$ ), are also significantly suppressed [56]. Further investigation showed that dexamethasone-induced activation of GR in myofibroblasts, but not in cancer cells, can nullify the proliferative effect of myofibroblasts on tumor cells and potentially inhibit epithelial-mesenchymal transition, but it is associated with pro-migratory behavior [57]. Apart from the tumor epithelium, paracrine factors from myofibroblasts also interact with the surrounding endothelial cells to promote cell motility and angiogenesis [58]. These activities are dampened by the conditioned medium from dexamethasone-treated myofibroblasts together with a decline in urokinase-type plasminogen activator and angiopoietin-like protein-2 [58]. In general, GR activation in myofibroblasts exhibits tumor-inhibiting effects. It is, however, noteworthy that current evidence for this phenomenon originated from one research group, rendering further validation pertinent.

\section{Nonsteroid hormone nuclear receptors - Anti-tumor properties of VDR, PPARY, RXR and FXR and pro-tumor effects of PPARB/ $\delta$ and $R A R \beta$ in CAF}

In addition to steroid hormone NRs, VDR in CAFs is also increasingly appreciated as a key anti-carcinogenic target. Ferrer-Mayorga et al. (2017) reported a positive correlation between the gene expression of stromal VDR with overall survival and progression-free survival in colorectal cancer [59]. Genes such as CD82 and S100A4, 
which are responsive to calcitriol in CAFs, are also associated with clinical outcomes and stromal VDR expression in patients with colorectal cancer, supporting a clinical value of VDR agonists in cancer treatment [59]. Conversely, pancreatic and hepatic TME is enriched by myofibroblast-like stellate cells, which upon activation, become proinflammatory, fibrogenic and tumor supportive $[60,61]$. Based on a transcriptomic analysis, calcipotriol, which is a nonhypercalcemic vitamin D analog, maintains the quiescent state and modifies the secretomes of pancreatic stellate cells by reducing the expression of inflammatory cytokines, ECM components, and growth factors [62]. Similar trends have also been observed in hepatic stellate cells [63, 64]. Combined therapy with gemcitabine plus calcipotriol tremendously improves the treatment outcomes of mice with orthotopic pancreatic ductal adenocarcinoma transplant, as evidenced by intratumoral aggregation of chemotherapy agents, a diminished tumor size and a higher survival rate [62]. A very recent report also suggests a regulatory role of VDR on CAF-liberated exosomal miRNA (e.g., miR-10a-5p and miR-181a-5p) [65]. Hence, exposure of CAFs to VDR ligands may modulate the stroma-tumor crosstalk not only via paracrine signaling but also by manipulation of the exosomal content. Despite promising results from preclinical studies, most clinical trials that employed vitamin D for cancer therapy and prevention have yielded underwhelming results, which reflects an inadequate understanding of VDR actions in both tumor and stromal cells [66-68]. Thus, an in-depth dissection of the biological roles of VDR in TME is critical to enable effective VDR-centric cancer treatment.

Several studies have also examined the activities of PPARs in CAFs. PPAR $\gamma$ has been found to be highly expressed in the myofibroblasts of colon adenocarcinoma biopsies, but not in normal colon tissues [69]. When hypoxic breast tumor cells are exposed to pioglitazone (PPARY agonist) and/or 6-OH-11-O-hydrophenanthrene (RXR agonist), the resultant exosomes are unable to trigger CAF activation compared with exosomes from tumor cells subjected to the control treatment, suggesting that these NR agonists can disrupt the tumor-stroma crosstalk [70]. In the same study, coactivation of PPARy and RXR in CAFs was found to effectively silence the pro-inflammatory response and metastatic phenotype by suppressing the expression of IL-6, carbonic anhydrase IX, metalloproteinase (MMP)-2 and MMP9 [70]. A similar anti-proliferative effect of PPARy activation on melanoma-derived CAFs has also been reported using the PPARY agonist 15d-PGJ2 [71]. Accordingly, activation of PPARy in CAFs could potentially act as a tumor suppressor by modifying the activation and supportive properties of CAFs in cancer development. Unlike PPAR $\gamma$, which is associated with anti-tumor effects upon ligand binding, PPAR $\beta / \delta$ in CAFs has a pro-tumor action. This phenomenon was clearly demonstrated in our recent study, in which the tumor burden was significantly lowered in fibroblast-specific PPAR $\beta / \delta$ knockout mice subjected to either chemical (azoxymethane or dextran sulfate sodium), genetic ( $\mathrm{APC}^{\mathrm{min} /+}$ ) or combinatory $\left(\mathrm{APC}^{\mathrm{min} /+}\right.$ with dextran sulfate sodium) tumorigenic induction [72]. Mechanistically, PPAR $\beta / \delta$ ablation in CAFs significantly escalates $\mathrm{H}_{2} \mathrm{O}_{2}$ liberation into the TME, exposing the tumor epithelium to increased oxidative stress to subsequently trigger NRF2-mediated signaling that attenuates tumor growth [72]. The regulatory effects of PPAR $\beta / \delta$ on oxidative stress, reactive oxygen species production, and antioxidant mechanism are in line with a previous study examining the wound microenvironment [73]. In short, both PPAR $\gamma$ and $\operatorname{PPAR} \beta / \delta$ in CAFs play a significant modulatory role in cancer development, of which the former acts on the local inflammation and cancer invasiveness while the latter alters the redox balance in TME.

FXR is an integral regulator of genes responsible for lipid, cholesterol and bile acid metabolism [74]. Loss of function of FXR is strongly linked to carcinogenesis in the liver, intestines and colorectal region where the receptor is highly expressed [75, 76]. Interestingly, in breast cancer cells exposed to the FXR agonist GW4064, conditioned medium from CAFs fail to promote enhanced growth, motility, and invasiveness [77]. This observation reflects a neutralizing effect of FXR activation on the tumorigenic paracrine signaling conferred by CAFs. Likewise, the characteristics of CAFs subjected to GW4064 are also profoundly altered. For instance, the genes involved in the cytoskeleton and cellular movement as well as a wide variety of growth factors are significantly downregulated, subsequently leading to loss of the tumor-supportive effects of CAFs [78]. The ability of an FXR inhibitor, guggulsterone, to completely reverse the GW4064-mediated anti-tumor effects further corroborates the necessity for FXR activation in eradicating the tumor-promoting features of CAFs [68]. In short, the evidence thus far for the benefits of FXR activation in CAFs is scarce, yet remarkably promising [78].

As mentioned earlier, our group has demonstrated that suppression of RAR $\beta$ in CAFs via genetic knockdown or with an antagonist named LE135 consistently lowers the chemoresistance of tumor cells that are otherwise promoted by wild-type/untreated CAFs [15]. This result also complements a previous study that concluded that RAR $\beta$ inhibition creates a hostile microenvironment that suppresses tumorigenesis through stromal remodeling, including impaired angiogenesis and reduced inflammatory cell recruitment and cancer-associated myofibroblast numbers [79]. In fact, our study also predicts that activation of VDR and GR, as well as inhibition of AR in 
CAFs, can potentiate the efficacy of chemotherapy, all of which are in excellent agreement with current understanding of these NRs in CAFs, as discussed previously. Collectively, based on preliminary data from various sources, NRs in CAFs or myofibroblasts are undoubtedly druggable targets that could serve as a new strategy to improve the clinical outcomes of pre-existing therapeutic approaches. For certain receptors such as AR and $E R \alpha$, their pro-oncogenic roles in CAF could be dependent on the cancer types and biochemical signals, resulting in the contradictory findings obtained thus far. Hence, diversifying the research to other cancer types and escalating cell-based methodology to preclinical animal study are commendable efforts to strengthen the concept and clinical prospects of CAF-oriented cancer therapy via NR inhibition.

\section{The steroid hormone nuclear receptors PPARs and RORY are crucial mediators of TAM and MDSC formation}

Apart from CAFs, TME is also occupied by numerous bone marrow-derived cells such as TAMs, MDSCs, neutrophils and tumor-infiltrating lymphocytes. Among these cells, TAMs and MDSCs are known to exhibit evident tumor-supporting and immune suppressive activities [80, 81]. Like CAFs, the steroid hormone NRs in TAMs also have profound impacts on cancer progression. It is widely accepted that TAMs, which more closely resemble alternatively activated M2 macrophages, are activated by Th2 cytokines such as IL-4, IL-10, and IL-13 [82]. M2 macrophage polarization is also promoted by exposure of the monocytes to glucocorticoids, which stimulates GR activation [83]. This process is accompanied by a significant downregulation of proteins linked to lysosomal activity, antigen presentation, and proinflammatory proteins, indicating immunosuppressive effects [83]. Additionally, GR also functions synergistically with p38MAPK to regulate the expression a CD20 homolog, MS4A8A, the overexpression of which in TAMs significantly enhances the tumor burden [84]. Taken together, classic GR signaling may play a dominant role in the tumor-supporting activities of TAMs.

In contrast to GR, the role of AR, ER, and PR-dependent tumorigenesis is poorly defined. The presence of TAMs influences the expression of ER $\alpha$, ER $\beta$ and PR in tumor cells [85-87]. Reciprocally, the number of TAMs also appears to be modulated by steroid hormone NRs of tumor cells, particularly ER [88]. Moreover, in wound healing and lung inflammatory studies, activation of AR, ER $\alpha$ and PR by their cognate steroid hormones would favor macrophage activation in an alternative manner, producing M2 macrophages that compel cellular repair and angiogenic processes [89-91]. The studies suggest that steroid hormones are vital determinants in the alternative differentiation of macrophages to modulate pulmonary inflammation and wound recovery. However, there is no direct evidence supporting the contribution of AR, ER, and PR to the formation of M2 macrophages in TME. Thus, future research should focus on explicating the roles of these NRs in TAM formation and tumor-supporting events.

The three isotypes of PPARs, PPAR $\alpha, \operatorname{PPAR} \beta / \delta$, and PPAR $\gamma$, are widely known to influence carcinogenic activities. However, current evidence is somewhat paradoxical concerning their roles in tumor cells, leading to the speculation that their actual functions could be dependent on the ligands, cancer types or even cancer stages [92]. In immune cells, PPARs also govern the fate of macrophage activation, likely because the maturation of macrophages is tightly linked to their metabolic state. To enable alternative activation of macrophages, immune cells must undergo oxidative metabolism, which is modulated by PPARs [93]. Macrophages that are unable to clear the metabolic checkpoint due to deletion of PPAR $\gamma, \operatorname{PPAR} \beta / \delta$ and PPAR $\gamma$ coactivator $1 \beta$ (PGC-1 13$)$, are incapable of expressing the alternative phenotype [94-96]. In contrast, treatment with PPAR $\alpha$ or $-\gamma$ agonists fosters the enrichment of M2-related biomarkers in macrophages [97]. Recently, a ligand-independent mechanism that involves PPARY in TAM differentiation has also been described, which involves the cleavage of PPAR $\gamma$ by caspase- 1 and thereby produces a $41-\mathrm{kDa}$ receptor fragment that translocates into mitochondria and interacts with medium-chain acyl-CoA dehydrogenase [98]. This interaction shuts down the enzyme and attenuates fatty acid oxidation, leading to intracellular aggregation of lipid droplets that drive TAM differentiation [98]. These results support the pro-tumor activities of PPAR $\gamma$ via promoting TAM formation. Likewise, PPAR $\beta / \delta$ also seems to follow a similar trajectory [99]. Notwithstanding, other empirical findings support a counterargument [100, 101]. The clinical use of thiazolidinedione is also not associated with an increased risk of many malignancies [102]. Collectively, the roles of PPARs in TAM differentiation and tumor progression undoubtedly remain an open topic necessitating further investigation.

RORs are classified as orphan NRs, which belong to a subfamily of thyroid hormone-like receptors. RORs are subcategorized into ROR $\alpha,-\beta$ and $-\gamma$, the last of which is highly expressed in thymus and lymphoid tissues and linked to immune cell differentiation and immune system regulation [103]. Interestingly, ROR $\gamma$ is also a crucial element in hematological malignancies. For example, RORy knockout mice are predisposed to thymic and lymphoblastic lymphomas [104, 105]. In addition, patients with multiple myeloma display an overexpression of ROR $\gamma$ in their peripheral blood mononuclear cells [106]. The roles of RORs in tumorigenesis vary in different 
cancers [103]. Nonetheless, in TME, activation of ROR $\gamma$ with an agonist (SR1078) promotes the formation of MDSCs and TAMs [107]. ROR $\gamma$-dependent myelopoiesis is mediated by key regulators such as Socs3, Bcl3, and $\mathrm{C} / \mathrm{EBP} \beta$, as well as macrophage-specific transcription factors, including IRF8 and PU.1 [107]. In the same study, ROR $\gamma$ could confer pro-tumor effects by shielding MDSCs from apoptotic death, promoting tumor growth and restricting tumor-infiltrating neutrophils, while ablation of the receptor successfully attenuates these processes [107]. These results position ROR $\gamma$ as an attractive target, and hence, the pharmacological effects of ROR $\gamma$ antagonists or inverse agonists in TAMs and MDSCs with respect to tumor development are of immense interest.

To summarize, research on NRs in TAMs or MDSCs is still in its infancy. Most of the available studies emphasize the effects of NRs on the fate of macrophage activation. This information is critical not only to inhibit the alternatively activated M2 macrophage pathway, which subsequently reduces the TAM count, but also to achieve reprogramming of M2 to M1 macrophages to initiate tumoricidal effects such as the induction of proinflammatory and anti-tumor immune responses in TME.

\section{Ceasing angiogenesis - targeting GR, PPAR and VDR of endothelial cells in TME}

The vascular endothelium is an essential tissue that maintains blood perfusion in addition to regulating the trafficking of nutrients and leukocytes to surrounding tissues. In TME, the integrity of the vascular endothelium is often jeopardized by factors such as hypoxia and chronic growth factor stimulation. Genetic abnormalities are also not uncommon in tumor endothelial cells [108]. As a cumulative result of atypical physiological conditions and genetic mutations, tumor endothelial cells differ significantly from normal endothelial cells by being highly proliferative, pro-angiogenic and more disorganized and leaky regarding the vasculature $[109,110]$.

Recent cancer research has identified PPARs as potential therapeutic targets and prognostic indicators for cancer therapy. Indeed, the expression of PPAR $\gamma$ is associated with slower progression and a lower incidence of tumor recurrence in bladder cancer [111]. This correlation is lost when certain angiogenic factors, namely, basic fibroblast growth factor and platelet-derived endothelial growth factor, are coexpressed in the tumors, indicating a possible role of PPAR $\gamma$ in angiogenesis in cancer progression by interacting with these growth factors [111]. Activation of PPAR $\gamma$ in endothelial cells is predominantly linked to anti-angiogenic activities, as exemplified by decreased expression of pro-angiogenic factors, reduced proliferation, impaired endothelial cell migration and tubule formation [112], but conflicting results have also been reported [113, 114]. Similar to
PPAR $\gamma$, fenofibrate-induced PPAR $\alpha$ activation in various tumor cell lines concomitantly suppresses proangiogenic vascular endothelial growth factor (VEGF) biosynthesis and increases anti-angiogenic thrombospondin 1 and endostatin [115]. These bioactivities are translated into reduced endothelial cell proliferation and neovascularization as well as impaired growth of the subcutaneous tumor xenograft in mice [115]. Unlike PPAR $\alpha$ and $-\gamma$, PPAR $\beta / \delta$ appears to be proangiogenic. Treatment with the PPAR $\beta / \delta$ ligand GW501516 promotes endothelial tube formation, whereas the maturation of microvessels in tumors is severely disrupted in PPAR $\beta / \delta$ knockout mice, leading to diminished blood flow to the tumors $[116,117]$. Taken together, all three isotypes of PPARs are actively involved in the angiogenesis performed by endothelial cells, which is one of the most critical processes in cancer development, sustaining the rapid expansion of tumor cells and opening the window for the metastatic process. However, the findings are not strictly based on tumor-derived endothelial cells. Given the functional variations between tumor-associated and normal endothelial cells, further validation is pertinent.

Next, VDR is closely associated with the development of endothelial cells in TME. In this context, calcitriol, which is an active metabolite of vitamin $\mathrm{D}$, has been widely studied regarding its roles in bone and mineral metabolism, as well as the differentiation of both normal and malignant cells. At a low dosage, calcitriol exhibits an anti-proliferative effect on cancer cells such as breast, colon, and prostrate while promoting differentiation, cell cycle arrest and eventually apoptosis [118]. A similar growth inhibitory effect has also been observed in tumor-derived endothelial cells, but not in normal ones [119]. Generally, increased levels of VDR ligands trigger a self-regulatory pathway by enhancing the expression of CYP-24b, a key enzyme in vitamin D catabolism [120]. As a result, VDR ligands are degraded and unable to trigger VDR-mediated anti-proliferative effects [121]. However, overexpression of CYP-24 has been reported in various cancers such as prostate, colon and breast cancer, explaining the varying calcitriol sensitivity and calcitriol resistance in these patients [122]. Moreover, the anti-proliferative effect of VDR in endothelial cells also relies on the epigenetic silencing of $C Y P-24$, which is achieved via hypermethylation at the $\mathrm{CpG}$ islands of CYP-24 promoter regions [123]. Transcriptional activation of $C Y P-24$ is prevented by the hypermethylation pattern, leading to growth inhibition in tumor-derived endothelial cells [123]. One study has also suggested a link between VDR and angiogenesis in TME modulated by a pro-oncogenic protein named DKK-4 [124]. The expression of DKK-4 is inversely correlated to that of VDR, while endothelial cells are more prone to migrate and form microvessels when they are exposed to 
conditioned medium from DKK-4-expressing cells [124]. The pro-tumor effects of DKK-4 are effectively eliminated by treatment with calcitriol. Thus, these studies support the use of VDR ligands that target the tumor endothelium with minimal disturbance to the normal vasculature.

Multiple studies have demonstrated the anti-angiogenic effects of glucocorticoids in normal and malignant cells, as well as during wound healing $[125,126]$. In tumor cells, glucocorticoids exert a direct inhibitory effect on the secretion of VEGF, which can be reversed by GR antagonist treatment [127]. This observation suggests that the anti-angiogenic effect is GR-dependent. Logie et al. (2010) reported that glucocorticoids have a negligible effect on the proliferation, viability and migration properties of endothelial cells, but instead, the hormone enhances thrombospondin-1 expression and impairs cell-cell contact, thus preventing the formation of endothelial tubules even in the presence of VEGF and prostaglandin $\mathrm{F}_{2 \mathrm{a}}$ [128]. The potent angiogenic inhibitory activity of GR has also prompted research on the nanosized drug delivery system to maximize the anti-tumor effect of GR [129].

Unlike GR, ER $\alpha$ is linked to the pro-angiogenic process in TME. Treatment with $17 \beta$-estradiol increases the vessel density and stabilizes the endothelium vasculature in tumors, making the blood vessels more resistant to insults from hypoxia and necrosis [130]. Increased neovascularization in the tumor environment ensures adequate oxygenation of the tumors and minimizes tumor cell death due to the hypoxic environment [130]. However, ER $\alpha$-dependent angiogenesis is primarily mediated by Tie2-expressing cells, which are not of hematopoietic origin [130]. Therefore, the true identity of Tie-2 positive cells in TME, and their relationship with tumor endothelial cells, remain to be clarified.

\section{Adipose cells are emerging players in tumor aggressiveness}

Adipocytes, also known as fat cells, are regulators of human physiological processes such as tissue homeostasis, and they are the primary site for energy storage in the form of intracellular triglycerides packaged in lipid droplets [131]. Additionally, they are also endocrine cells that secrete hormones and cytokines to regulate human physiological processes such as inflammation and the reproductive system [132]. The functions of adipose cells in TME resemble those of fat depots, but in a tumor-supportive manner [133]. Emerging evidence also supports a role for dysfunctional adipose tissues in field cancerization mediated by prolonged local inflammation [134]. However, our understanding of the role of adipose cells in TME is still considerably limited.

One recent study has shown that the recruitment of preadipocytes occurs more readily in prostate cancer cells than normal prostate tissues, a process that enhances the invasiveness of prostate cancer in mice with orthotopic xenografts [135]. Mechanistically, neighboring adipocytes significantly increase the expression of miRNA-301a in tumor cells, which serves to suppress AR signaling in these cells [135]. The inhibition of AR signaling is followed by alterations in the gene expression of TGF- $\beta$ via the serine/threonine kinase receptor or TGF- $\beta$ receptor and its downstream genes such as Smad3 and matrix-metalloproteinase-9, fueling metastatic processes [135]. Coculturing human Simpson Golabi Behmel Syndrome (SGBS) preadipocyte cells, which are considered to be a representative in vitro model of white preadipocytes, and ER-positive MCF7 breast cancer cells results in the suppression of ER $\alpha$ expression in MCF7 cells [136]. Cohabitation of preadipocytes and MCF7 cells also significantly enhances the epithelial-mesenchymal transition of MCF7 tumor cells, as documented by overexpression of FOXC2 and TWIST1, and changes in $\mathrm{N}$ - and E-cadherin expression [136]. As a consequence, the expression of HIF $\alpha$, TGF- $\beta$ and lectin-type oxidized LDL receptor 1 in SGBS adipocytes are elevated [136]. Both studies have demonstrated that the presence of adipose cells in TME can impact both NR signaling and oncogenic processes in cancer cells. However, the studies did not aim to delineate the activities of NRs in tumor-associated adipose cells and their contribution to cancer progression, an aspect that has been minimally explored to date. In light of the emerging roles of adipose cells in field cancerization as well as the predominant actions of various NRs in adipocyte biology, it will be interesting to unearth this relationship.

\section{Implications of existing research for stroma-directed anticancer therapy via nuclear receptor manipulation}

For years, targeting the tumor epithelium has been the sole cornerstone of cancer research, which has resulted in the clinical use of aggressive therapeutic methods such as surgery, radiation and chemotherapy to eliminate cancerous cells regardless of the inflicted extensive collateral damage. However, the effectiveness of traditional anti-cancer strategies is increasingly challenged by treatment failures such as interpatient responsiveness, onset of chemoresistance, and local and distal recurrence, which are partly attributable to the genetic heterogeneity and genome instability of tumors and continuous tumor evolution [137]. Tumor evolution follows a Darwinian model, which also predicts the insufficiency of targeting the cancer epithelium alone, underscoring the need for alternative therapeutic strategies.

Stroma-directed anticancer therapy will require a different therapeutic approach aimed at multiple and interacting cells. Stromal cells are generally considered to be more genetically stable, and thus the occurrence of 
mutations that may lead to resistance to drug treatments are minimal compared with the large tumor mutation burden observed in cancer cells. By consolidating the NR profile of various stromal cells across different tumor types, we can highlight NRs that have been thus far identified to regulate the assistive properties of tumor stroma in carcinogenesis, as summarized in Table 1 and Fig. 2. Certain NRs are clearly consistently observed across different tumor types; for instance, VDR, PPARs, ER, GR and AR in CAFs, as well as GR and PPARs in TAMs and endothelial cells. Modulating the activities of these NRs in stromal cells may potentially serve as a common adjunct therapy for the treatment of a wide range of cancers. In this context, by targeting NRs in stromal cells, the resultant physiological changes and drug responses could be more predictable, explaining why selected NRs, notably PPARs and GR, are consistently found to be crucial modulators of tumorigenesis in a cancer type-independent manner.

For stroma-directed therapy to be a viable strategy as part of a multimodality approach or as adjunctive treatment to conventional tumor treatment, we also need to address the relative population of different stromal cells in different tumor types. For example, CAFs are relatively rare in brain, renal and ovarian cancers. In such instances, the depletion of CAFs or the disruption of CAF functions is likely to provide only marginal benefits. Similarly, while next-generation cancer treatment using immunotherapies such as PD-1 checkpoint blockade and Chimeric Antigen Receptor T-cell (CART) therapy are swiftly gaining attention, the efficacy of CAR-T therapy is dependent on the immune cell interactions in the TME $[138,139]$. A recent characterization of immune infiltrates has shown that tumor genotypes, such as the tumor mutation burden, determine immunophenotypes and tumor escape mechanisms [140]. In cases where immunotherapy is less successful, stroma-directed therapy targeting other stromal cells may rise to be the predominant player. Moreover, if the efficacy and universality of stroma-directed therapy by targeting NRs are validated, the strategy can even be used to treat rare cancers simply because of the comparable physiological functionality of stromal cells in TME. These speculations and effectiveness of NR-based stroma-directed therapy can be further tested by extensive exploration of the NR signatures in TME across different types of cancers.

\section{Limitations, challenges, and future perspectives}

To a certain extent, manipulating NRs of key tumorsupporting cells can sensitize tumor cells to anti-cancer treatments by interfering with the stroma-tumor crosstalk. However, current knowledge is still too incomplete for reliable translation into favorable clinical outcomes for different cancer types because of several limitations.
First, the available data are derived primarily from hormone-dependent tumors, most notably breast and prostate cancers. Hence, our understanding of the roles of NRs in TME is fundamentally based on cancer-associated cells that are more actively involved in steroid hormone modulation and signaling. The effects of steroids differ from cancer to cancer [141], raising concerns about the generalizability of the results to cancers that are less hormone-dependent. Second, concerning the abovementioned limitation, current findings mostly include studies of steroid hormone NRs such as GR, ER, AR, and PR, because the development of hormone-dependent cancers is highly sensitive to steroids, facilitating detection of the biological roles of steroid receptors in tumorigenesis. As a result, our knowledge about NRs in TME is markedly skewed towards steroid receptors. In contrast, orphan NRs such as ERRs, RORs and LRH-1 have demonstrated a strong linkage with carcinogenesis [142]. However, exploiting them as a potential cancer therapy is underappreciated due to the lack of well-characterized ligands. This situation is anticipated to change in the near future because the US Food and Drug Administration has recently approved the first use of RNA-based gene silencing drug (siRNA) to knock down the expression of defective transthyretin for the treatment of polyneuropathy in patients with hereditary transthyretin-mediated amyloidosis [143, 144]. Given that targeting orphan NRs with RNA interference technology could someday become a therapeutic option, the recent approval is believed to have sparked more intensive research on the impacts of orphan NR suppression in cancer development.

Furthermore, the roles of NRs in TME have been established mainly based on cell culture studies via coculturing methods or with the use of conditioned medium from tumor-supporting cells. Empirical data from in vivo animal studies of TME are limited because cell-specific activation or inhibition of an NR, especially with a pharmacological approach, is remarkably challenging in animal models. Although genetic engineering can be used to obtain targeted stimulation or knockdown in animals [36, 37], it is associated with tedious preparation, relatively high costs and arduous administration, rendering this approach less desirable in actual clinical settings compared with the use small molecules. However, cell-specific modulation of the specifically targeted NR is crucial because the same receptor can have opposing effects in different cancer-associated cells. This phenomenon is demonstrated by GR, the activation of which in cancer-associated myofibroblasts reduces tumor proliferation [57] but promotes the M2 phenotype in macrophages, thus contributing to TAM differentiation and consequently tumor promotion [83]. Hence, given the heterogeneity of cellular populations in TME and their diverse physiological response to NR 


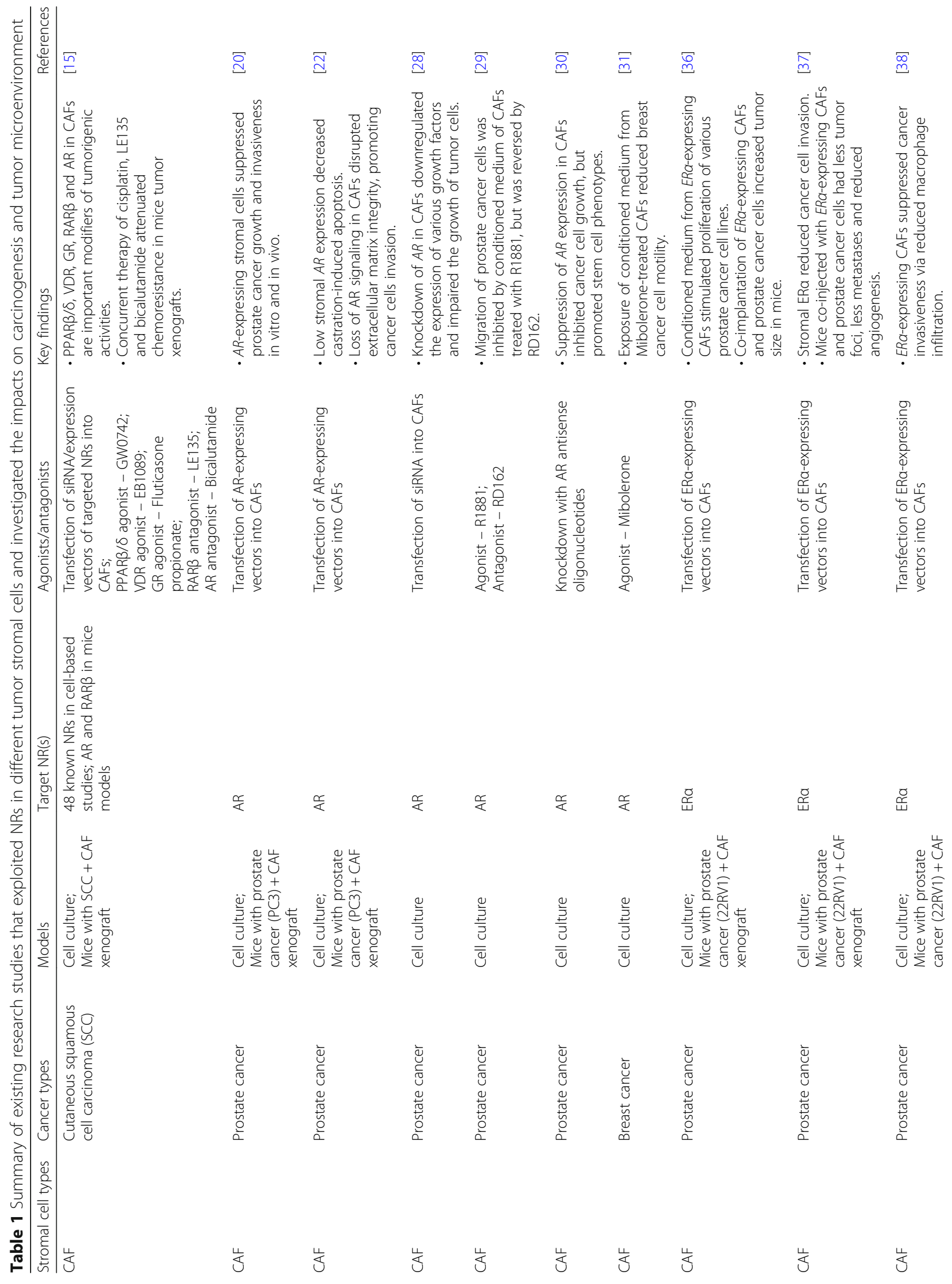




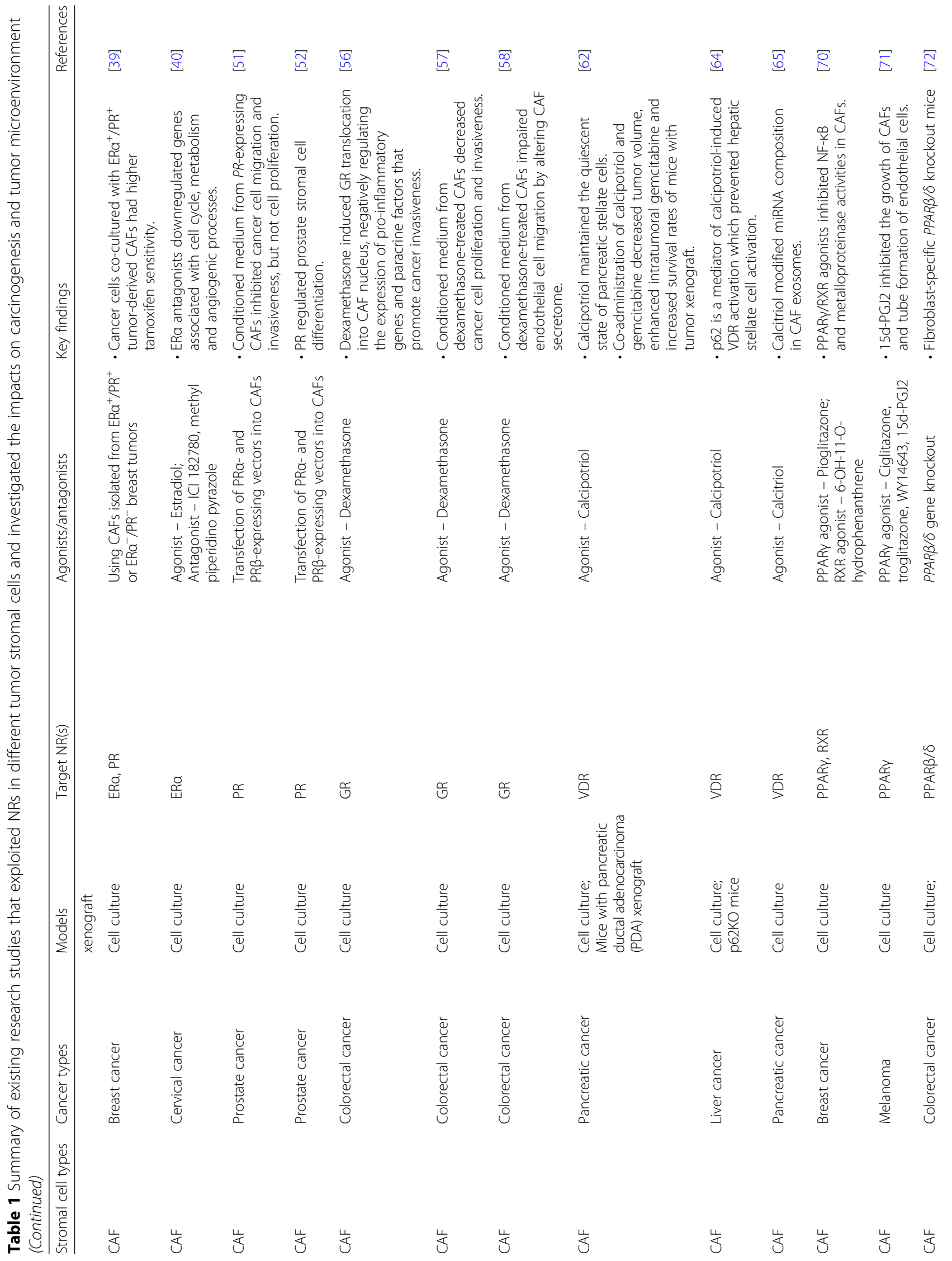




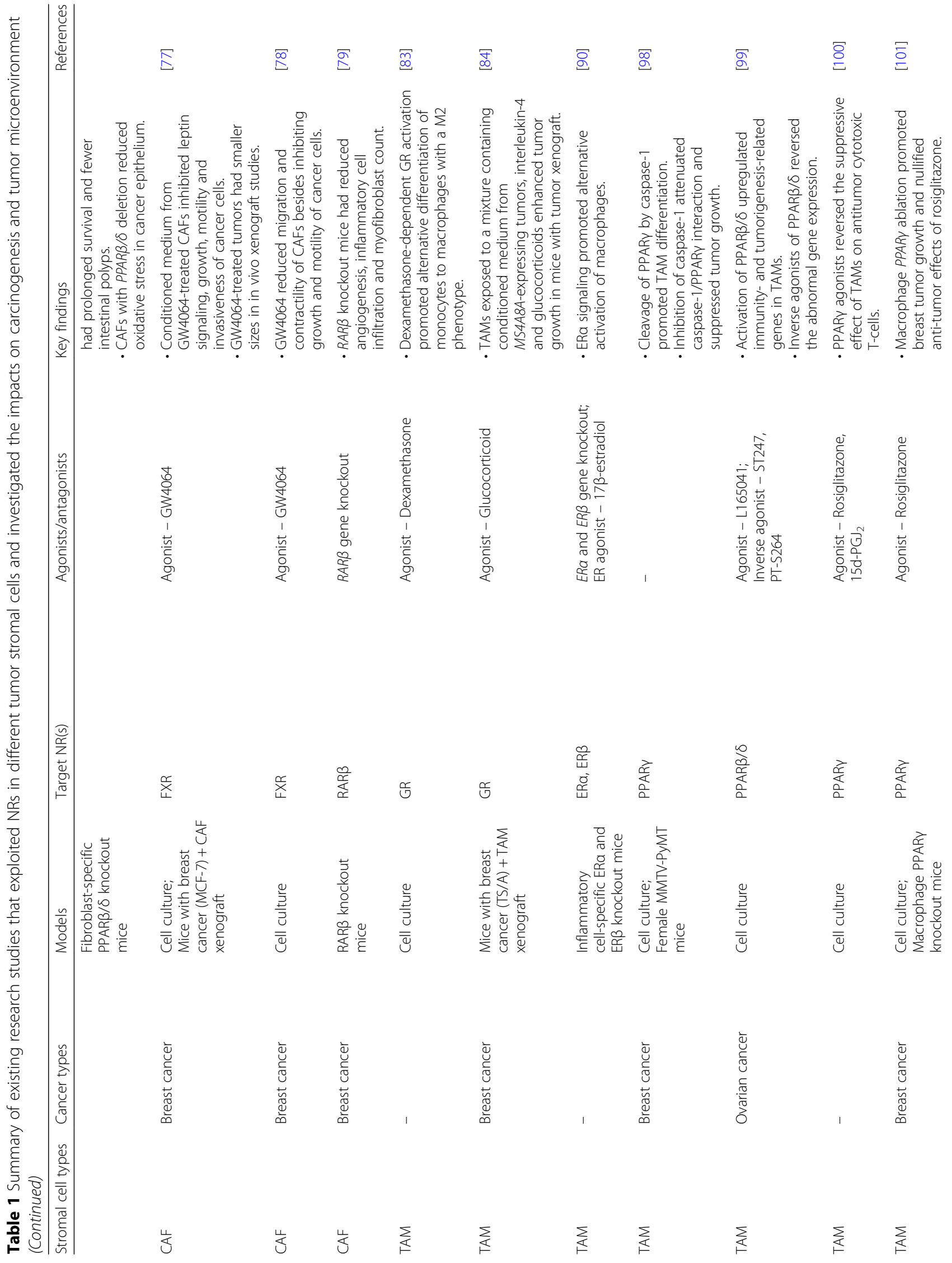


Ching et al. Molecular Cancer $\quad$ (2019) 18:51

Page 13 of 19

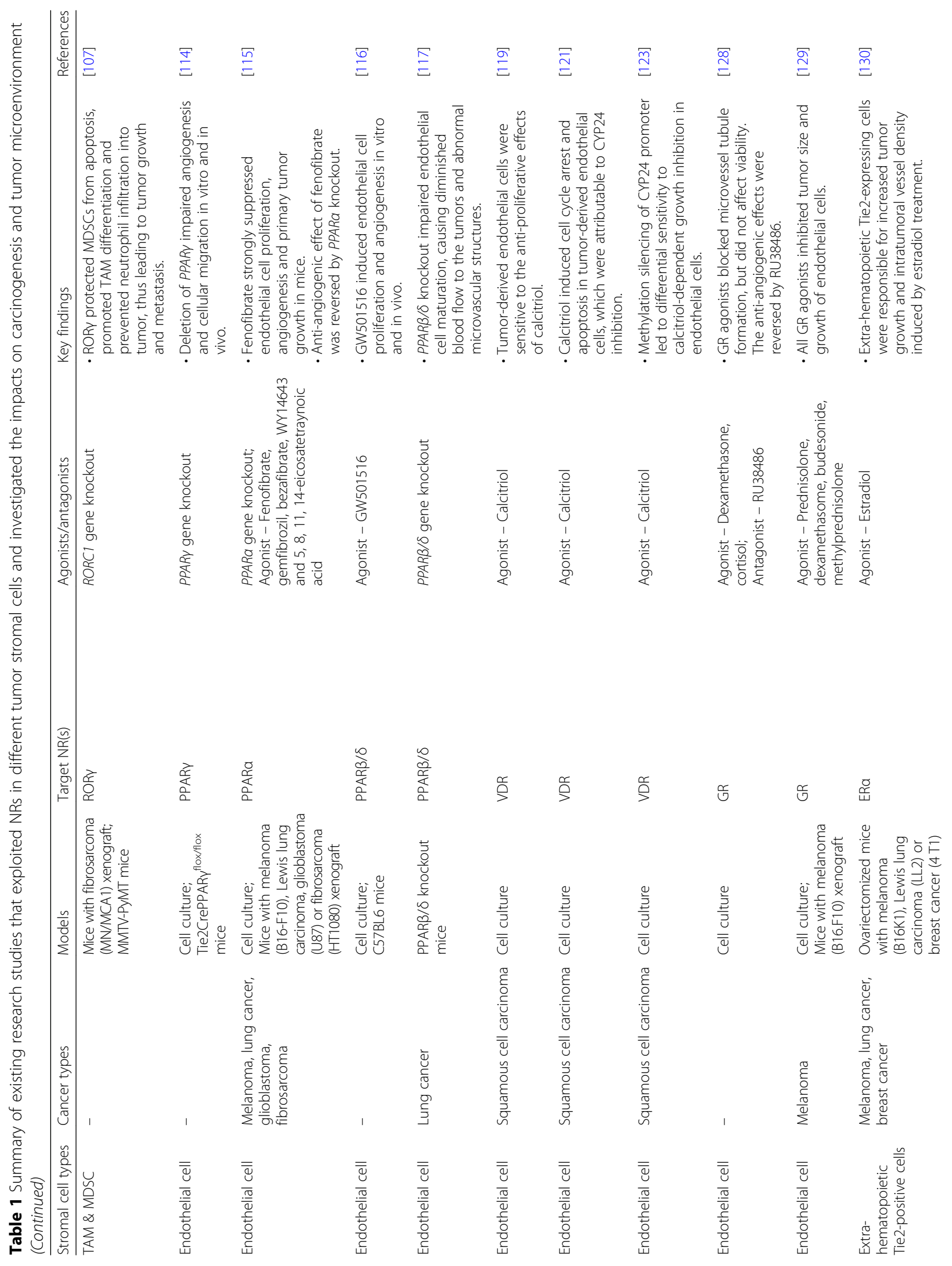




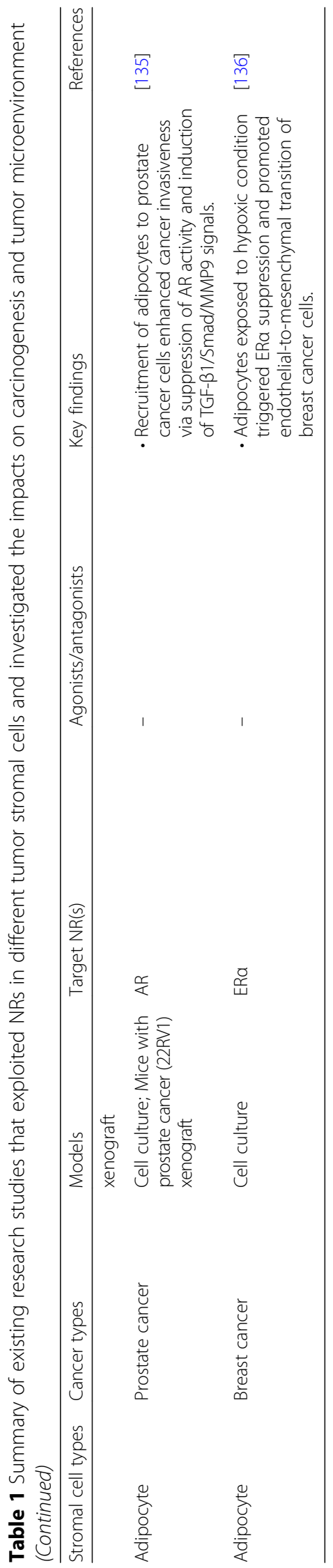




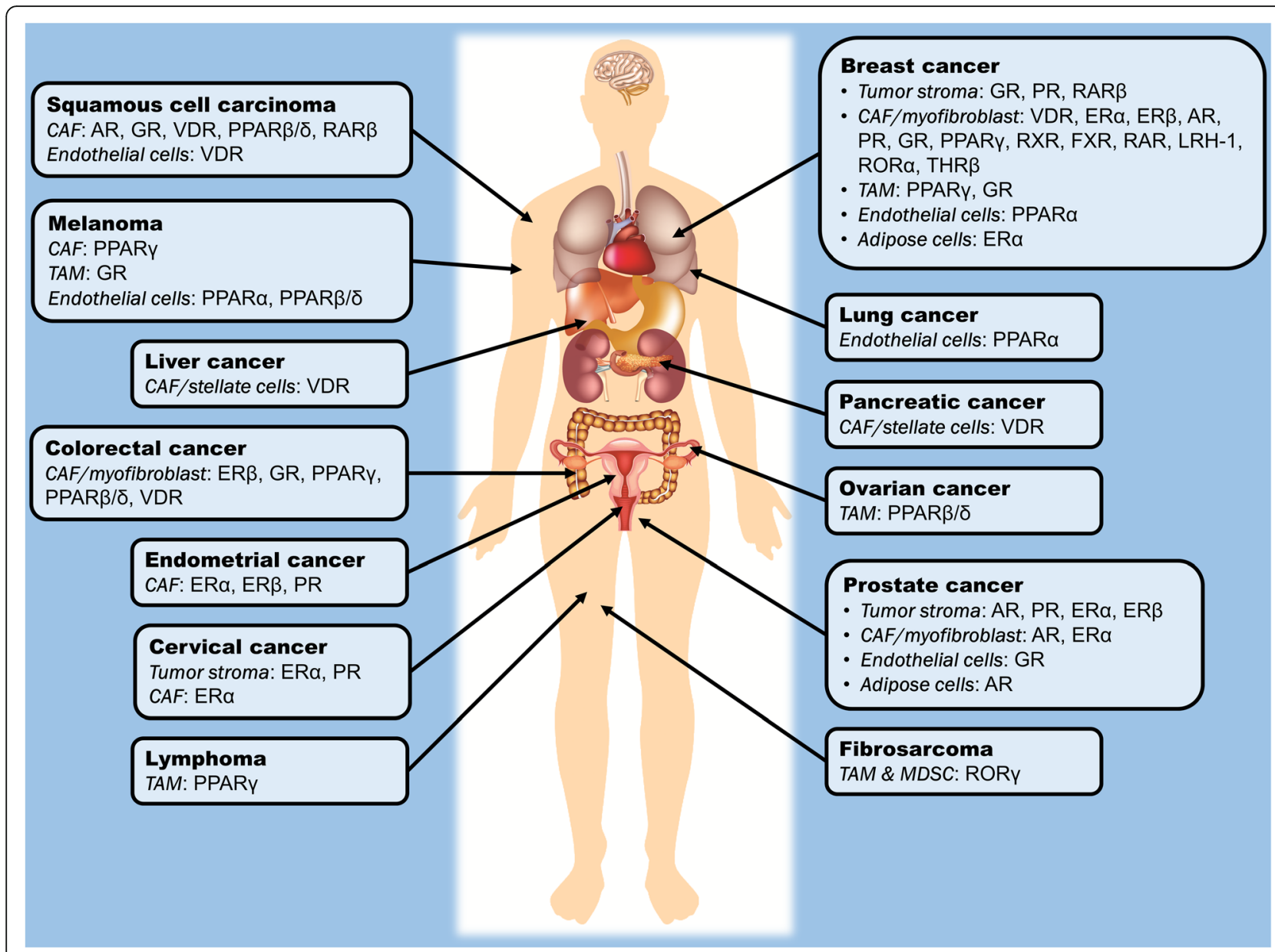

Fig. 2 Summary of the so far identified nuclear receptors in the tumor microenvironment which play an active role in the modulation of oncogenic processes in different cancer types. AR, androgen receptor; CAF, cancer-associated fibroblast; ER, estrogen receptor; FXR, farnesoid X receptor; GR, glucocorticoid receptor; LHR-1, liver homolog receptor-1; MDSC, myeloid-derived suppressive cells; PPAR, peroxisome proliferatoractivated receptor; PR, progesterone receptor; RAR, retinoic acid receptor; ROR, RAR-related orphan receptor; RXR, retinoic X receptor; TAM, tumorassociated macrophage; THR, thyroid hormone receptor; VDR, vitamin D receptor

modulation, future research should also focus on the development of cell-specific drug delivery to achieve targeted manipulation of NR signaling in relevant cells.

The effects of NRs in TME on exosomes have scarcely been explored. Considering the vital roles of exosomes in cell-cell communication, which mediates various oncogenic processes, it is worthwhile to investigate how NR signaling in cancer-supporting cells calibrates the stroma-tumor interaction by regulating the exosomal content and liberation. Additionally, stroma-tumor communication is a dynamic and reciprocal action. Therefore, understanding how neighboring cancer cells affect NR signaling in the cancer-associated cells and downstream functional alterations can further reveal the true nature of TME. Essentially, in-depth dissection of the interplay between tumor-supporting cells and malignant cells may reveal additional exploitable targets to improve cancer therapy.

\section{Conclusions}

NRs of tumor-supporting cells in TME play an essential role in various oncogenic processes. The NR signature of TME can serve as a crucial marker to pinpoint the fragility of the disease and guide the therapeutic strategy, with the ultimate goal of improving cancer prognosis. In light of the striking druggability of NRs, the future clinical prospect of developing a TME-oriented cancer therapy by targeting these receptors is promising. Among the $48 \mathrm{NRs}$ in humans, the oncogenic functions of VDR, PPARs, AR, ER and GR in tumor-supporting cells are the best-characterized to date. Evidence of other receptors, such as RAR $\beta, R O R \gamma$, and FXR, is limited yet promising. Given the heterogeneity of cellular populations within TME, more intensive research in understanding the molecular mechanisms of cell-cell interactions and how to 
master intercellular communication is of paramount importance. The ability to exploit NRs in TME in a highly specific and precise manner, in this case, can lay the foundation for precision medicine in cancer therapy and may even allow us to transform tumor-supporting cells into tumor foes.

\section{Abbreviations}

AR: Androgen receptor; CAF: Cancer-associated fibroblast; ECM: Extracellular matrix; ER: Estrogen receptor; FXR: Farnesoid X receptor; GR: Glucocorticoid receptor; IL: Interleukin; LRH-1: Liver receptor homolog-1; MDSC: Myeloidderived suppressor cells; NR: Nuclear receptor; PGC-1 $\beta$ : PPARy coactivator $1 \beta$; PPAR: Peroxisome proliferator-activated receptor; PR: Progesterone receptor; RAR: Retinoic acid receptor; ROR: RAR-related orphan receptor; RXR: Retinoic $X$ receptor; TAM: Tumor-associated macrophage; TGF $\beta$ : Transforming growth factor $\beta$; TME: Tumor microenvironment; TNFa: Tumor necrosis factor a; VDR: Vitamin D receptor; VEGF: Vascular endothelial growth factor

\section{Acknowledgments}

Not applicable.

\section{Funding}

This work was supported by Singapore Ministry of Education under Singapore Ministry of Education Academic Research Fund Tier 2 (2014-T2-1012; 2017-T1-002-103) and Academic Research Fund Tier 1 (2015-T1-001034) to NST, and by the Lee Kong Chian School of Medicine, Nanyang Technological University Start-up Grant to WW

\section{Availability of data and materials}

Not applicable.

\section{Authors' contributions}

NST and WW designed the framework of the review. HSC and JXTL collected related studies and drafted the manuscript. NST, WW, HSC and JXTL participated in the manuscript editing. All authors have read and approved the final manuscript, and consent to publish.

\section{Ethics approval and consent to participate} Not applicable.

\section{Consent for publication}

Not applicable.

\section{Competing interests}

The authors declare that they have no competing interests.

\section{Publisher's Note}

Springer Nature remains neutral with regard to jurisdictional claims in published maps and institutional affiliations.

\section{Author details}

${ }^{1}$ School of Biological Sciences, Nanyang Technological University Singapore, 60 Nanyang Drive, Singapore 637551, Singapore. ${ }^{2}$ Lee Kong Chian School of Medicine, Nanyang Technological University Singapore, 11 Mandalay Road, Singapore 308232, Singapore. ${ }^{3}$ INRA ToxAlim, UMR1331, Chemin de Tournefeuille, Toulouse Cedex 3, France. ${ }^{4}$ Center for Integrative Genomics, University of Lausanne, Le Génopode, CH-1015 Lausanne, Switzerland.

Received: 12 December 2018 Accepted: 21 February 2019

Published online: 30 March 2019

\section{References}

1. Metivier R, Reid G, Gannon F. Transcription in four dimensions: nuclear receptor-directed initiation of gene expression. EMBO Rep. 2006;7:161-7.

2. Sever R, Glass CK. Signaling by nuclear receptors. Cold Spring Harb Perspect Biol. 2013;5:a016709.

3. Stender JD, Kim K, Charn TH, Komm B, Chang KCN, Kraus WL, et al. Genome-wide analysis of estrogen receptor a DNA binding and tethering mechanisms identifies Runx1 as a novel tethering factor in receptormediated transcriptional activation. Mol Cell Biol. 2010;30:3943-55.

4. Gadaleta RM, Magnani L. Nuclear receptors and chromatin: an inducible couple. J Mol Endocrinol. 2014;52:R137.

5. Richer JK, Jacobsen BM, Manning NG, Abel MG, Wolf DM, Horwitz KB. Differential gene regulation by the two progesterone receptor isoforms in human breast cancer cells. J Biol Chem. 2002;277:5209-18.

6. Strand DW, Jiang M, Murphy TA, Yi Y, Konvinse KC, Franco OE, et al. PPARY isoforms differentially regulate metabolic networks to mediate mouse prostatic epithelial differentiation. Cell Death Dis. 2012;3:e361.

7. Dhiman VK, Bolt MJ, White KP. Nuclear receptors in cancer uncovering new and evolving roles through genomic analysis. Nat Rev Genet. 2017:19:160.

8. Long MD, Campbell MJ. Pan-cancer analyses of the nuclear receptor superfamily. Nucl Receptor Res. 2015:2:101182.

9. Chen $F$, Zhuang $X$, Lin $L, Y u$ P, Wang $Y$, Shi $Y$, et al. New horizons in tumor microenvironment biology: challenges and opportunities. BMC Med. 2015;13:45.

10. Eyden B. The myofibroblast: phenotypic characterization as a prerequisite to understanding its functions in translational medicine. J Cell Mol Med. 2008;12:22-37.

11. Gascard P, Tlsty TD. Carcinoma-associated fibroblasts: orchestrating the composition of malignancy. Genes Dev. 2016;30:1002-19.

12. Liao Z, Tan ZW, Zhu P, Tan NS. Cancer-associated fibroblasts in tumor microenvironment - Accomplices in tumor malignancy. Cell Immunol. 2018; (17)30222-8. https://doi.org/10.1016/j.cellimm.2017.12.003.

13. Knower KC, Chand AL, Eriksson N, Takagi K, Miki Y, Sasano H, et al. Distinct nuclear receptor expression in stroma adjacent to breast tumors. Breast Cancer Res Treat. 2013;142:211-23.

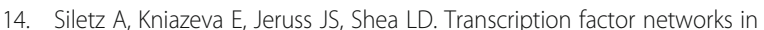
invasion-promoting breast carcinoma-associated fibroblasts. Cancer Microenviron. 2013:6:91-107.

15. Chan JSK, Sng MK, Teo ZQ, Chong HC, Twang JS, Tan NS. Targeting nuclear receptors in cancer-associated fibroblasts as concurrent therapy to inhibit development of chemoresistant tumors. Oncogene. 2017;37:160.

16. Leach D, Buchanan G. Stromal androgen receptor in prostate cancer development and progression. Cancers. 2017;9:10.

17. Olapade-Olaopa EO, MacKay EH, Taub NA, Sandhu DPS, Terry TR, Habib FK. Malignant transformation of human prostatic epithelium is associated with the loss of androgen receptor immunoreactivity in the surrounding stroma. Clin Cancer Res. 1999;5:569-76.

18. Henshall SM, Quinn DI, Lee CS, Head DR, Golovsky D, Brenner PC, et al. Altered expression of androgen receptor in the malignant epithelium and adjacent stroma is associated with early relapse in prostate cancer. Cancer Res. 2001:61:423-7.

19. Ricciardelli C, Choong CS, Buchanan G, Vivekanandan S, Neufing P, Stahl J, et al. Androgen receptor levels in prostate cancer epithelial and peritumoral stromal cells identify non-organ confined disease. Prostate. 2005:63:19-28.

20. Li Y, Li CX, Ye H, Chen F, Melamed J, Peng Y, et al. Decrease in stromal androgen receptor associates with androgen-independent disease and promotes prostate cancer cell proliferation and invasion. J Cell Mol Med. 2008;12:2790-8.

21. Wikström P, Marusic J, Stattin P, Bergh A. Low stroma androgen receptor level in normal and tumor prostate tissue is related to poor outcome in prostate cancer patients. Prostate. 2009;69:799-809.

22. Leach DA, Need EF, Toivanen R, Trotta AP, Palenthorpe HM, Tamblyn DJ, et al. Stromal androgen receptor regulates the composition of the microenvironment to influence prostate cancer outcome. Oncotarget. 2015;6:16135-50.

23. Grossmann M, Cheung AS, Zajac JD. Androgens and prostate cancer; pathogenesis and deprivation therapy. Best Pract Res Clin Endocrinol Metab. 2013:27:603-16.

24. Nash C, Boufaied N, Mills IG, Franco OE, Hayward SW, Thomson AA. Genome-wide analysis of AR binding and comparison with transcript expression in primary human fetal prostate fibroblasts and cancer associated fibroblasts. Mol Cell Endocrinol. 2018:471:1-14.

25. Berry PA, Maitland NJ, Collins AT. Androgen receptor signalling in prostate: effects of stromal factors on normal and cancer stem cells. Mol Cell Endocrinol. 2008;288:30-7.

26. Shigemura K, Isotani S, Wang R, Fujisawa M, Gotoh A, Marshall FF, et al. Soluble factors derived from stroma activated androgen receptor 
phosphorylation in human prostate LNCaP cells: roles of ERK/MAP kinase. Prostate. 2009;69:949-55.

27. Eder T, Weber A, Neuwirt $H$, Grünbacher G, Ploner C, Klocker $H$, et al. Cancer-associated fibroblasts modify the response of prostate cancer cells to androgen and anti-androgens in three-dimensional spheroid culture. Int J Mol Sci. 2016;17:1458.

28. Yu S, Xia S, Yang D, Wang K, Yeh S, Gao Z, et al. Androgen receptor in human prostate cancer-associated fibroblasts promotes prostate cancer epithelial cell growth and invasion. Med Oncol. 2013;30:674.

29. Cioni B, Nevedomskaya E, Melis MHM, Burgsteden J, Stelloo S, Hodel E, et al. Loss of androgen receptor signaling in prostate cancer-associated fibroblasts (CAFs) promotes CCL2- and CXCL8-mediated cancer cell migration. Mol Oncol. 2018;12:1308-23.

30. Liao C-P, Chen L-Y, Luethy A, Kim Y, Kani K, MacLeod AR, et al. Androgen receptor in cancer-associated fibroblasts influences stemness in cancer cells. Endocr Relat Cancer. 2017;24:157.

31. Lanzino M, Campana A, Giordano C, Barone I, Bonofiglio D, Catalano S, et al. Expression and function of androgen receptor in human breast cancerassociated fibroblasts: may androgens shape breast tumor microenvironment? FASEB J. 2016;30:698.699.

32. Subramaniam KS, Tham ST, Mohamed Z, Woo YL, Mat Adenan NA, Chung I. Cancer-associated fibroblasts promote proliferation of endometrial cancer cells. PLoS One. 2013;8:e68923.

33. Hong M-K, Wang J-H, Su C-C, Li M-H, Hsu Y-H, Chu T-Y. Expression of estrogen and progesterone receptor in tumor stroma predicts favorable prognosis of cervical squamous cell carcinoma. Int J Gynecol Cancer. 2017;27:1247-55.

34. Daniels G, Gellert LL, Melamed J, Hatcher D, Li Y, Wei J, et al. Decreased expression of stromal estrogen receptor $a$ and $\beta$ in prostate cancer. Am J Transl Res. 2014;6:140-6.

35. Tzelepi V, Grivas P, Kefalopoulou Z, Kalofonos H, Varakis JN, Melachrinou M, et al. Estrogen signaling in colorectal carcinoma microenvironment: expression of ERB1, AIB-1, and TIF-2 is upregulated in cancer-associated myofibroblasts and correlates with disease progression. Virchows Arch. 2009:454:389-99.

36. Da J, Lu M, Wang Z. Estrogen receptor alpha (ERa)-associated fibroblasts promote cell growth in prostate cancer. Cell Biochem Biophys. 2015; $73: 793-8$

37. Slavin S, Yeh C-R, Da J, Yu S, Miyamoto H, Messing EM, et al. Estrogen receptor a in cancer-associated fibroblasts suppresses prostate cancer invasion via modulation of thrombospondin 2 and matrix metalloproteinase 3. Carcinogenesis. 2014;35:1301-9.

38. Yeh C-R, Slavin S, Da J, Hsu I, Luo J, Xiao G-Q, et al. Estrogen receptor a in cancer associated fibroblasts suppresses prostate cancer invasion via reducing CCL5, IL6 and macrophage infiltration in the tumor microenvironment. Mol Cancer. 2016;15:7.

39. Shekhar MPV, Santner S, Carolin KA, Tait L. Direct involvement of breast tumor fibroblasts in the modulation of tamoxifen sensitivity. Am J Pathol. 2007;170:1546-60

40. Kumar MM, Davuluri S, Poojar S, Mukherjee G, Bajpai AK, Bafna UD, et al. Role of estrogen receptor alpha in human cervical cancer-associated fibroblasts: a transcriptomic study. Tumor Biol. 2016;37:4409-20.

41. Annicotte J-S, Chavey C, Servant N, Teyssier J, Bardin A, Licznar A, et al. The nuclear receptor liver receptor homolog-1 is an estrogen receptor target gene. Oncogene. 2005;24:8167.

42. Chand AL, Herridge KA, Howard TL, Simpson ER, Clyne CD. Tissue-specific regulation of aromatase promoter II by the orphan nuclear receptor $\mathrm{LRH}-1$ in breast adipose stromal fibroblasts. Steroids. 2011;76:741-4.

43. Speirs V, Skliris GP, Burdall SE, Carder PJ. Distinct expression patterns of $E R a$ and $E R \beta$ in normal human mammary gland. J Clin Pathol. 2002;55:371-4.

44. Palmieri C, Saji S, Sakaguchi H, Cheng G, Sunters A, O'Hare M, et al. The expression of oestrogen receptor (ER)-beta and its variants, but not ERalpha, in adult human mammary fibroblasts. J Mol Endocrinol. 2004;33:35.

45. Cheng G, Weihua Z, Warner M, Gustafsson J-Å. Estrogen receptors ERa and ERß in proliferation in the rodent mammary gland. Proc Natl Acad Sci U S A. 2004;101:3739-46

46. Sapino A, Bosco M, Cassoni P, Castellano I, Arisio R, Cserni G, et al. Estrogen receptor- $\beta$ is expressed in stromal cells of fibroadenoma and phyllodes tumors of the breast. Mod Pathol. 2006;19:599.

47. Omoto $\mathrm{Y}$, Iwase $\mathrm{H}$. Clinical significance of estrogen receptor $\beta$ in breast and prostate cancer from biological aspects. Cancer Sci. 2015;106:337-43.
48. Ellem SJ, Risbridger GP. The dual, opposing roles of estrogen in the prostate. Ann N Y Acad Sci. 2009;1155:174-86.

49. Wada-Hiraike $\mathrm{O}$, Hiraike $\mathrm{H}$, Okinaga $\mathrm{H}$, Imamov $\mathrm{O}$, Barros RPA, Morani $\mathrm{A}$, et al. Role of estrogen receptor $\beta$ in uterine stroma and epithelium: insights from estrogen receptor $\beta^{-/-}$mice. Proc Natl Acad Sci U S A. 2006;103:18350-5.

50. Mohammed H, Russell IA, Stark R, Rueda OM, Hickey TE, Tarulli GA, et al. Progesterone receptor modulates ERa action in breast cancer. Nature. 2015;523:313.

51. Yu Y, Lee JS, Xie N, Li E, Hurtado-Coll A, Fazli L, et al. Prostate stromal cells express the progesterone receptor to control cancer cell mobility. PLoS One. 2014;9:e92714.

52. Yu Y, Yang O, Fazli L, Rennie PS, Gleave ME, Dong X. Progesterone receptor expression during prostate cancer progression suggests a role of this receptor in stromal cell differentiation. Prostate. 2015;75:1043-50.

53. Smith RA, Lea RA, Weinstein SR, Griffiths LR. Progesterone, glucocorticoid, but not estrogen receptor mRNA is altered in breast cancer stroma. Cancer Lett. 2007;255:77-84.

54. Bamberger A-M, Milde-Langosch K, Löning T, Bamberger CM. The glucocorticoid receptor is specifically expressed in the stromal compartment of the human endometrium. J Clin Endocrinol Metab. 2001;86:5071.

55. Catteau X, Simon P, Buxant F, Noël J-C. Expression of the glucocorticoid receptor in breast cancer-associated fibroblasts. Mol Clin Oncol. 2016:5:372-6.

56. Drebert Z, Bracke M, Beck IM. Glucocorticoids and the non-steroidal selective glucocorticoid receptor modulator, compound a, differentially affect colon cancer-derived myofibroblasts. J Steroid Biochem Mol Biol. 2015;149:92-105.

57. Drebert Z, De Vlieghere E, Bridelance J, De Wever O, De Bosscher K, Bracke $\mathrm{M}$, et al. Glucocorticoids indirectly decrease colon cancer cell proliferation and invasion via effects on cancer-associated fibroblasts. Exp Cell Res. 2018;362:332-42.

58. Drebert Z, MacAskill M, Doughty-Shenton D, De Bosscher K, Bracke M, Hadoke PWF, et al. Colon cancer-derived myofibroblasts increase endothelial cell migration by glucocorticoid-sensitive secretion of a promigratory factor. Vasc Pharmacol. 2017;89:19-30.

59. Ferrer-Mayorga G, Gómez-López G, Barbáchano A, Fernández-Barral A, Peña C, Pisano DG, et al. Vitamin D receptor expression and associated gene signature in tumour stromal fibroblasts predict clinical outcome in colorectal cancer. Gut. 2017;66:1449-62.

60. Apte MV Wilson JS. Dangerous liaisons: pancreatic stellate cells and pancreatic cancer cells. J Gastroenterol Hepatol. 2012;27:69-74.

61. Coulouarn C, Clément B. Stellate cells and the development of liver cancer: therapeutic potential of targeting the stroma. J Hepatol. 2014;60:1306-9.

62. Sherman Mara H, Yu Ruth T, Engle Dannielle D, Ding N, Atkins Annette $\mathrm{R}$, Tiriac $\mathrm{H}$, et al. Vitamin $\mathrm{D}$ receptor-mediated stromal reprogramming suppresses pancreatitis and enhances pancreatic cancer therapy. Cell. 2014:159:80-93.

63. Abramovitch S, Dahan-Bachar L, Sharvit E, Weisman $Y$, Tov AB, Brazowski E, et al. Vitamin $D$ inhibits proliferation and profibrotic marker expression in hepatic stellate cells and decreases thioacetamide-induced liver fibrosis in rats. Gut. 2011:60:1728-37.

64. Duran A, Hernandez Eloy D, Reina-Campos M, Castilla Elias A, Subramaniam S, Raghunandan S, et al. p62/SQSTM1 by binding to vitamin D receptor inhibits hepatic stellate cell activity, fibrosis, and liver cancer. Cancer Cell. 2016:30:595-609.

65. Kong F, Li L, Wang G, Deng X, Li Z, Kong X. VDR signaling inhibits cancerassociated-fibroblasts' release of exosomal miR-10a-5p and limits their supportive effects on pancreatic cancer cells. Gut. 2018. https://doi.org/10. 1136/gutjnl-2018-316627.

66. Gee J, Bailey H, Kim K, Kolesar J, Havighurst T, Tutsch KD, et al. Phase II open label, multi-center clinical trial of modulation of intermediate endpoint biomarkers by 1a-hydroxyvitamin D2 in patients with clinically localized prostate cancer and high grade pin. Prostate. 2013;73:970-8.

67. Rejnmark L, Bislev LS, Cashman KD, Eiríksdottir G, Gaksch M, Grübler M, et al. Non-skeletal health effects of vitamin D supplementation: a systematic review on findings from meta-analyses summarizing trial data. PLoS One. 2017;12:e0180512

68. Scher HI, Jia X, Chi K, Rd W, Berry WR, Albers P, et al. Randomized, openlabel phase III trial of docetaxel plus high-dose calcitriol versus docetaxel plus prednisone for patients with castration-resistant prostate cancer. J Clin Oncol. 2011;29:2191-8. 
69. Vandoros GP, Konstantinopoulos PA, Sotiropoulou-Bonikou G, Kominea A, Papachristou Gl, Karamouzis MV, et al. PPAR-gamma is expressed and NF-kB pathway is activated and correlates positively with COX-2 expression in stromal myofibroblasts surrounding colon adenocarcinomas. J Cancer Res Clin Oncol. 2006;132:76-84.

70. Papi A, De Carolis S, Bertoni S, Storci G, Sceberras V, Santini D, et al. PPARY and RXR ligands disrupt the inflammatory cross-talk in the hypoxic breast cancer stem cells niche. J Cell Physiol. 2014;229:1595-606.

71. Paulitschke V, Gruber S, Hofstätter E, Haudek-Prinz V, Klepeisz P, Schicher N, et al. Proteome analysis identified the PPARy ligand 15d-PGJ2 as a novel drug inhibiting melanoma progression and interfering with tumor-stroma interaction. PLoS One. 2012;7:e46103.

72. Tan EHP, Sng MK, How ISB, Chan JSK, Chen J, Tan CK, et al. ROS release by PPAR $\beta / \delta$-null fibroblasts reduces tumor load through epithelial antioxidant response. Oncogene. 2018;37:2067-78.

73. Wang $X$, Sng MK, Foo S, Chong HC, Lee WL, Tang MBY, et al. Early controlled release of peroxisome proliferator-activated receptor $\beta / \delta$ agonist GW501516 improves diabetic wound healing through redox modulation of wound microenvironment. J Control Release. 2015;197:138-47.

74. Forman BM, Goode E, Chen J, Oro AE, Bradley DJ, Perlmann T, et al. Identification of a nuclear receptor that is activated by farnesol metabolites. Cell. 1995;81:687-93.

75. Maran RRM, Thomas A, Roth M, Sheng Z, Esterly N, Pinson D, et al. Farnesoid $X$ receptor deficiency in mice leads to increased intestinal epithelial cell proliferation and tumor development. J Pharmacol Exp Ther. 2009:328:469-77.

76. Yang F, Huang X, Yi T, Yen Y, Moore DD, Huang W. Spontaneous development of liver tumors in the absence of the bile acid receptor Farnesoid X receptor. Cancer Res. 2007;67:863-7.

77. Giordano C, Barone I, Vircillo V, Panza S, Malivindi R, Gelsomino L, et al. Activated FXR inhibits leptin signaling and counteracts tumor-promoting activities of cancer-associated fibroblasts in breast malignancy. Sci Rep. 2016;6:21782.

78. Barone I, Vircillo V, Giordano C, Gelsomino L, Győrffy B, Tarallo R, et al. Activation of Farnesoid $X$ receptor impairs the tumor-promoting function of breast cancer-associated fibroblasts. Cancer Lett. 2018;437:89-99.

79. Liu X, Nugoli M, Laferrière J, Saleh SM, Rodrigue-Gervais IG, Saleh M, et al. Stromal retinoic acid receptor $\beta$ promotes mammary gland tumorigenesis. Proc Natl Acad Sci U S A. 2011:108:774-9.

80. Liu Y, Cao X. The origin and function of tumor-associated macrophages. Cell Mol Immunol. 2014;12:1.

81. Veglia F, Perego M, Gabrilovich D. Myeloid-derived suppressor cells coming of age. Nat Immunol. 2018;19:108-19.

82. Yang $L$, Zhang $Y$. Tumor-associated macrophages: from basic research to clinical application. J Hematol Oncol. 2017;10:58.

83. Heideveld E, Hampton-O'Neil LA, Cross SJ, van Alphen FPJ, van den Biggelaar M, Toye AM, et al. Glucocorticoids induce differentiation of monocytes towards macrophages that share functional and phenotypical aspects with erythroblastic island macrophages. Haematologica. 2018;103:395-405.

84. Schmieder A, Schledzewski K, Michel J, Tuckermann JP, Tome L, Sticht C, et al. Synergistic activation by p38MAPK and glucocorticoid signaling mediates induction of M2-like tumor-associated macrophages expressing the novel CD20 homolog MS4A8A. Int J Cancer. 2011;129:122-32.

85. X-f J, Q-I T, H-g L, Shen X-m, Luo X, Wang X-y, et al. Tumor-associated macrophages correlate with progesterone receptor loss in endometrial endometrioid adenocarcinoma. J Obstet Gynaecol Res. 2013;39:855-63.

86. Tong $H$, Ke J-Q, Jiang F-Z, Wang X-J, Wang F-Y, Li Y-R, et al. Tumorassociated macrophage-derived CXCL8 could induce ERa suppression via HOXB13 in endometrial cancer. Cancer Lett. 2016;376:127-36.

87. Lindsten T, Hedbrant A, Ramberg A, Wijkander J, Solterbeck A, Eriksson M, et al. Effect of macrophages on breast cancer cell proliferation, and on expression of hormone receptors, UPAR and HER-2. Int J Oncol. 2017:51:104-14.

88. Ciucci A, Zannoni GF, Buttarelli M, Lisi L, Travaglia D, Martinelli E, et al. Multiple direct and indirect mechanisms drive estrogen-induced tumor growth in high grade serous ovarian cancers. Oncotarget. 2016;7:8155-71.

89. Becerra-Díaz M, Strickland AB, Keselman A, Heller NM. Androgen and androgen receptor as enhancers of $\mathrm{M} 2$ macrophage polarization in allergic lung inflammation. J Immunol. 2018;201:2923-33.

90. Campbell L, Emmerson E, Williams H, Saville CR, Krust A, Chambon P, et al. Estrogen receptor-alpha promotes alternative macrophage activation during cutaneous repair. J Invest Dermatol. 2014;134:2447-57.
91. Routley CE, Ashcroft GS. Effect of estrogen and progesterone on macrophage activation during wound healing. Wound Repair Regen. 2009;17:42-50.

92. Youssef J, Badr M. Peroxisome proliferator-activated receptors and cancer: challenges and opportunities. Br J Pharmacol. 2011;164:68-82.

93. Chawla A. Control of macrophage activation and function by PPARs. Circ Res. 2010;106:1559-69.

94. Odegaard Jl, Ricardo-Gonzalez RR, Goforth MH, Morel CR, Subramanian V, Mukundan L, et al. Macrophage-specific PPARy controls alternative activation and improves insulin resistance. Nature. 2007;447:1116.

95. Odegaard Jl, Ricardo-Gonzalez RR, Red Eagle A, Vats D, Morel CR, Goforth $\mathrm{MH}$, et al. Alternative $\mathrm{M} 2$ activation of Kupffer cells by PPAR $\delta$ ameliorates obesity-induced insulin resistance. Cell Metab. 2008;7:496-507.

96. Vats D, Mukundan L, Odegaard Jl, Zhang L, Smith KL, Morel CR, et al. Oxidative metabolism and PGC-1 $\beta$ attenuate macrophage-mediated inflammation. Cell Metab. 2006:4:13-24.

97. Penas F, Mirkin GA, Vera M, Cevey Á, González CD, Gómez Ml, et al. Treatment in vitro with PPARa and PPARy ligands drives M1-to-M2 polarization of macrophages from T. Cruzi-infected mice. Biochim Biophys Acta. 2015;1852:893-904

98. Niu Z, Shi Q, Zhang W, Shu Y, Yang N, Chen B, et al. Caspase-1 cleaves PPARY for potentiating the pro-tumor action of TAMs. Nat Commun. 2017;8:766.

99. Tim S, Till A, Annika W, Florian F, Sonja L, Evelyn S, et al. Deregulation of PPAR $/ \delta$ target genes in tumor-associated macrophages by fatty acid ligands in the ovarian cancer microenvironment. Oncotarget. 2015;6:13416-33.

100. Van Ginderachter JA, Meerschaut S, Liu Y, Brys L, De Groeve K, Hassanzadeh Ghassabeh $G$, et al. Peroxisome proliferator-activated receptor $\gamma$ (PPAR $Y$ ) ligands reverse CTL suppression by alternatively activated (M2) macrophages in cancer. Blood. 2006;108:525-35

101. Cheng WY, Huynh H, Chen P, Peña-Llopis S, Wan Y. Macrophage PPARY inhibits Gpr132 to mediate the anti-tumor effects of rosiglitazone. eLife. 2016;5:e18501

102. Monami M, Dicembrini I, Mannucci E. Thiazolidinediones and cancer: results of a meta-analysis of randomized clinical trials. Acta Diabetol. 2014;51:91-101.

103. Fan J, Lv Z, Yang G, Liao Tt XJ, Wu F, et al. Retinoic acid receptor-related orphan receptors: critical roles in tumorigenesis. Front Immunol. 2018;9: 1187. https://doi.org/10.3389/fimmu.2018.01187.

104. Ueda E, Kurebayashi S, Sakaue M, Backlund M, Koller B, Jetten AM. High incidence of T-cell lymphomas in mice deficient in the retinoid-related orphan receptor RORy. Cancer Res. 2002;62:901-9.

105. Liljevald M, Rehnberg M, Söderberg M, Ramnegård M, Börjesson J, Luciani $D$, et al. Retinoid-related orphan receptor $\gamma$ (RORY) adult induced knockout mice develop lymphoblastic lymphoma. Autoimmun Rev. 2016;15:1062-70.

106. Feng $P$, Yan $R$, Dai $X$, Xie $X$, Wen $H$, Yang S. The alteration and clinical significance of Th1/Th2/Th17/Treg cells in patients with multiple myeloma. Inflammation. 2015;38:705-9.

107. Strauss L, Sangaletti S, Consonni Francesca M, Szebeni G, Morlacchi S, Totaro Maria G, et al. RORC1 regulates tumor-promoting "emergency" granulo-monocytopoiesis. Cancer Cell. 2015;28:253-69.

108. Hida K, Hida Y, Amin DN, Flint AF, Panigrahy D, Morton CC, et al. Tumorassociated endothelial cells with cytogenetic abnormalities. Cancer Res. 2004;64:8249-55.

109. Hashizume H, Baluk P, Morikawa S, McLean JW, Thurston G, Roberge S, et al. Openings between defective endothelial cells explain tumor vessel leakiness. Am J Pathol. 2000;156:1363-80.

110. Hida K, Maishi N, Torii C, Hida Y. Tumor angiogenesis-characteristics of tumor endothelial cells. Int J Clin Oncol. 2016;21:206-12.

111. Possati L, Rocchetti R, Talevi S, Beatrici V, Margiotta C, Ferrante L, et al. The role of peroxisome proliferator-activated receptor $\gamma$ in bladder cancer in relation to angiogenesis and progression. Gen Pharmacol. 2000;35:269-75.

112. Kotlinowski J, Jozkowicz A. PPAR gamma and angiogenesis: endothelial cells perspective. J Diabetes Res. 2016:2016:11.

113. Pich C, Meylan P, Mastelic-Gavillet B, Nguyen NT, Loyon R, Trang BK, et al. Induction of paracrine signaling in metastatic melanoma cells by PPARY agonist rosiglitazone activates stromal cells and enhances tumor growth. Cancer Res. 2018;78(22):6447-61. https://doi.org/10.1158/0008-5472.CAN-18-0912

114. Vattulainen-Collanus S, Akinrinade O, Li M, Koskenvuo M, Li CG, Rao SP, et al. Loss of PPARy in endothelial cells leads to impaired angiogenesis. J Cell Sci. 2016;129:693-705 
115. Panigrahy D, Kaipainen A, Huang S, Butterfield CE, Barnés CM, Fannon M, et al. PPARa agonist fenofibrate suppresses tumor growth through direct and indirect angiogenesis inhibition. Proc Natl Acad Sci U S A. 2008;105:985-90.

116. Piqueras L, Reynolds Andrew R, Hodivala-Dilke Kairbaan M, Alfranca A, Redondo Juan $M$, Hatae $T$, et al. Activation of PPAR $\beta / \delta$ induces endothelial cell proliferation and angiogenesis. Arterioscler Thromb Vasc Biol. 2007;27:63-9.

117. Müller-Brüsselbach S, Kömhoff M, Rieck M, Meissner W, Kaddatz K, Adamkiewicz J, et al. Deregulation of tumor angiogenesis and blockade of tumor growth in PPARß-deficient mice. EMBO J. 2007;26:3686-98.

118. Díaz L, Díaz-Muñoz M, García-Gaytán A, Méndez I. Mechanistic effects of calcitriol in cancer biology. Nutrients. 2015;7:5020.

119. Chung I, Wong MK, Flynn G, Yu W-d, Johnson CS, Trump DL. Differential antiproliferative effects of calcitriol on tumor-derived and matrigel-derived endothelial cells. Cancer Res. 2006:66:8565-73.

120. Peng X, Tiwari N, Roy S, Yuan L, Murillo G, Mehta RR, et al. Regulation of CYP24 splicing by 1,25-dihydroxyvitamin D3 in human colon cancer cells. Endocrinol. 2012;212:207.

121. Chung I, Yu W-D, Karpf AR, Flynn G, Bernardi RJ, Modzelewski RA, et al. Antiproliferative effects of calcitriol on endothelial cells derived from two different microenvironments. J Steroid Biochem Mol Biol. 2007:103:768-70.

122. Jeon S-M, Shin E-A. Exploring vitamin D metabolism and function in cancer. Exp Mol Med. 2018;50:20

123. Chung I, Karpf AR, Muindi JR, Conroy JM, Nowak NJ, Johnson CS, et al. Epigenetic silencing of CYP24 in tumor-derived endothelial cells contributes to selective growth inhibition by calcitriol. J Biol Chem. 2007;282:8704-14.

124. Pendás-Franco N, García JM, Peña C, Valle N, Pálmer HG, Heinäniemi M, et al. DICKKOPF-4 is induced by TCF/ $\beta$-catenin and upregulated in human colon cancer, promotes tumour cell invasion and angiogenesis and is repressed by 1a,25-dihydroxyvitamin D3. Oncogene. 2008;27:4467.

125. Small GR, Hadoke PWF, Sharif I, Dover AR, Armour D, Kenyon CJ, et al. Preventing local regeneration of glucocorticoids by $11 \beta$-hydroxysteroid dehydrogenase type 1 enhances angiogenesis. Proc Natl Acad Sci U S A 2005;102:12165-70

126. Yano A, Fujii Y, Iwai A, Kageyama Y, Kihara K. Glucocorticoids suppress tumor angiogenesis and in vivo growth of prostate cancer cells. Clin Cancer Res. 2006;12:3003-9.

127. Iwai A, Fujii Y, Kawakami S, Takazawa R, Kageyama Y, Yoshida MA, et al. Down-regulation of vascular endothelial growth factor in renal cell carcinoma cells by glucocorticoids. Mol Cell Endocrinol. 2004;226:11-7.

128. Logie JJ, Ali S, Marshall KM, Heck MMS, Walker BR, Hadoke PWF. Glucocorticoid-mediated inhibition of angiogenic changes in human endothelial cells is not caused by reductions in cell proliferation or migration. PLoS One. 2011;5:e14476.

129. Banciu M, Metselaar JM, Schiffelers RM, Storm G. Liposomal glucocorticoids as tumor-targeted anti-angiogenic nanomedicine in B16 melanoma-bearing mice. J Steroid Biochem Mol Biol. 2008;111:101-10.

130. Péqueux C, Raymond-Letron I, Blacher S, Boudou F, Adlanmerini M, Fouque $\mathrm{M}-\mathrm{J}$, et al. Stromal estrogen receptor-a promotes tumor growth by normalizing an increased angiogenesis. Cancer Res. 2012;72:3010-9.

131. Hepler C, Vishvanath L, Gupta RK. Sorting out adipocyte precursors and their role in physiology and disease. Genes Dev. 2017;31:127-40.

132. Coelho M, Oliveira T, Fernandes R. Biochemistry of adipose tissue: an endocrine organ. Arch Med Sci. 2013;9:191-200.

133. Cozzo AJ, Fuller AM, Makowski L. Contribution of adipose tissue to development of cancer. In: Pollock DM. Compr Physiol. 2017. https://doi org/10.1002/cphy.c170008.

134. Lengyel E, Makowski L, DiGiovanni J, Kolonin MG. Cancer as a matter of fat: the crosstalk between adipose tissue and tumors. Trends Cancer. 2018;4:374-84.

135. Xie H, Li L, Zhu G, Dang Q, Ma Z, He D, et al. Infiltrated preadipocytes increase prostate cancer metastasis via modulation of the miR-301a/androgen receptor (AR)/TGF- $31 / \mathrm{Smad} / \mathrm{MMP9}$ signals. Oncotarget. 2015;6:12326-39.

136. Yao-Borengasser A, Monzavi-Karbassi B, Hedges RA, Rogers LJ, Kadlubar SA, Kieber-Emmons T. Adipocyte hypoxia promotes epithelial-mesenchymal transition-related gene expression and estrogen receptor-negative phenotype in breast cancer cells. Oncol Rep. 2015;33:2689-94.

137. Burrell RA, McGranahan N, Bartek J, Swanton C. The causes and consequences of genetic heterogeneity in cancer evolution. Nature. 2013;501:338-45.

138. D'Aloia MM, Zizzari IG, Sacchetti B, Pierelli L, Alimandi M. CAR-T cells: the long and winding road to solid tumors. Cell Death Dis. 2018;9:282.
139. Cristescu R, Mogg R, Ayers M, Albright A, Murphy E, Yearley J, et al. Pantumor genomic biomarkers for PD-1 checkpoint blockade-based immunotherapy. Science. 2018;362:eaar3593.

140. Varn FS, Wang Y, Mullins DW, Fiering S, Cheng C. Systematic pan-cancer analysis reveals immune cell interactions in the tumor microenvironment. Cancer Res. 2017;77:1271-82.

141. Ahmad N, Kumar R. Steroid hormone receptors in cancer development: a target for cancer therapeutics. Cancer Lett. 2011;300:1-9.

142. Baek SH, Kim Kl. Emerging roles of orphan nuclear receptors in cancer. Annu Rev Physiol. 2014;76:177-95.

143. U.S. Food and Drug Administration. FDA approves first-of-its kind targeted RNA-based therapy to treat a rare disease. 2018. https://www. fda.gov/newsevents/newsroom/pressannouncements/ucm616518.htm. Accessed 30 Nov 2018.

144. Charoentong P, Finotello F, Angelova M, Mayer C, Efremova M, Rieder D, et al. Pan-cancer immunogenomic analyses reveal genotypeimmunophenotype relationships and predictors of response to checkpoint blockade. Cell Rep. 2017;18:248-62.
Ready to submit your research? Choose BMC and benefit from:

- fast, convenient online submission

- thorough peer review by experienced researchers in your field

- rapid publication on acceptance

- support for research data, including large and complex data types

- gold Open Access which fosters wider collaboration and increased citations

- maximum visibility for your research: over $100 \mathrm{M}$ website views per year

At $\mathrm{BMC}$, research is always in progress.

Learn more biomedcentral.com/submissions 